\title{
Specialty-level Factors Historically Influencing Telehealth Use Can Provide Implications for Sustainability in a Post-Pandemic Era: A Systematic Review and Narrative Synthesis
}

Pavani Rangachari ( $\sim$ prangachari@augusta.edu )

Augusta University https://orcid.org/0000-0002-9464-7299

Swapandeep S. Mushiana

University of San Francisco - School of Nursing and Health Professions

Krista Herbert

Rowan University

\section{Research article}

Keywords: Telehealth use, adoption, medical specialties, contextual factors, hospital organizations, specialty societies, provider culture, patient-centered care, telehealth sustainability, post-pandemic

Posted Date: January 20th, 2021

DOl: https://doi.org/10.21203/rs.3.rs-149558/v1

License: (c) (1) This work is licensed under a Creative Commons Attribution 4.0 International License.

Read Full License 


\section{Abstract}

Background: Recent studies in the US have found wide variation in telehealth use across medical specialties (e.g., $6.1 \%$ in Allergy-Immunology vs. $24.1 \%$ in Cardiology). This is a problem-of-interest, because the US lacks a standardized set of telehealth reimbursement policies, which in turn has hindered telehealth use across all specialties. Despite these policy-level constraints experienced by all specialties, some have normalized telehealth use to mainstream practice, while others are just getting started during the pandemic. Despite accelerated telehealth use during COVID-19 through removal of federal coverage restrictions, uncertainties remain regarding future sustainability. This paper conducts a systematic review to identify "specialty-level factors" historically influencing telehealth use, with a view to identifying implications for widespread sustainability in the post-pandemic era.

Methods: We conducted a systematic review and narrative synthesis to examine factors historically influencing telehealth use across six medical specialties in the US, including three "lower-using" specialties (Allergy-Immunology, Gastroenterology, Family Medicine) and three "higher-using" specialties (Cardiology, Psychiatry, Radiology). The "macro-meso-micro" framework was used to guide the review. Article searches were conducted on PubMed. The PRISMA checklist was used to guide reporting of literature reviewed. Three reviewers worked to develop a preliminary synthesis, identify eligibility criteria, explore themes in the data, and assess robustness of final synthesis.

Results: Fifty-three articles were reviewed across six medical specialties. The review identified 12 factors across 3 layers, including: 1) macro-layer (policy-level, legal, other-structural), 2) meso-layer (specialtyleve/ historical telehealth rationale, hospital-organizational, specialty-society, treatment, technological, research, cultural) and 3) micro-layer (individual-level provider-and-patient-specific) factors. A key finding was that among "higher-using" medical specialties, the specialty societies and hospital organizations in the meso-layer, proactively promoted telehealth use by influencing both macro-and micro-layerfactors (e.g., advocating for consistent payment policies and enabling provider practices to be more tech-savvy \& patient-centric, respectively).

Conclusion: By identifying a comprehensive set of contextual, individual (and interaction) factors influencing telehealth use across six medical specialties, this review addresses a gap and provides a foundation for future research. Importantly, it identifies: 1) strategies for reducing variation in telehealth use across medical specialties, and 2) implications for ensuring widespread sustainability in the postpandemic era.

\section{Introduction}

The United States (US) Health Resources Services Administration (HRSA) defines telehealth as the use of electronic information and telecommunications technologies to support long-distance clinical health care, patient and professional health-related education, public health and health administration. [1, 2] According to HRSA, telehealth refers to a broad scope of remote healthcare services that encompasses 
telemedicine. While telemedicine refers specifically to remote clinical services, telehealth can refer to remote clinical as well as non-clinical services, such as provider training and continuing education. [1] However, since federal payers in the US use the term "telemedicine" and the literature on this topic is still nascent and growing, some literatures have drawn subtle distinctions between the two terms, depending on the scope of work, while others have viewed telemedicine as a form of telehealth and used the two terms interchangeably. $[3,4]$ Since the interest here, is in examining telehealth use in general across medical specialties, the broader concept of telehealth is most relevant to this paper. As such, the terms "telehealth" and "telemedicine" are used interchangeably, in this paper.

Telehealth is known to help patients overcome two barriers they face when seeking health care: distance and time. [5] Additionally, telehealth has been found to deliver a range of benefits, including improved access to healthcare, more timely interactions between providers and patients, improved continuity of care, better health outcomes, higher patient \& provider satisfaction, and more efficient use time, to name a few. [6] Proponents of telehealth have argued that it has the potential to transform healthcare delivery by reducing costs and increasing quality and patient satisfaction. $[5,6]$

In the United States, although telehealth was a 'hot topic' before COVID-19, its use was far from widespread, and was limited to certain medical specialties. [7-9] For example, a pre-pandemic US-based weighted survey study on use of telemedicine by individual physicians in their practice (published in Health Affairs in 2018), found wide variations in the use of telemedicine (for physician-patient interactions) by medical specialty, ranging from a low of $6.1 \%$ in the internal medicine subspecialty of Allergy-Immunology to a high of $39.5 \%$ in Radiology. Other "lower-using" specialties identified by the study were Gastroenterology (7.9\%), OB/GYN (9.3\%), General Surgery (9.7\%), and Family Medicine (11.8\%). On the other hand, other "higher-using" specialties included Psychiatry (27.8\%), the internal medicine subspecialty of Cardiology (24.1\%), Pathology (23\%) and Emergency Medicine (22.3\%). [7] The results of this study have already been widely cited in the general telehealth literature and corroborated by evidence and position statements in the specialty-specific telehealth literature as well. [10-15]

The wide variation in telehealth use across medical specialties is intriguing, since the US lacks a nationwide standardized set of telehealth reimbursement policies, which in turn, has historically posed a barrier to telehealth adoption in all specialties. [16] Despite these macro (policy-level) constraints experienced by all medical specialties, some specialties have been able to normalize telehealth to mainstream practice (e.g., Psychiatry, Cardiology); while others are just getting started during the COVID19 pandemic (e.g., Allergy-Immunology), despite potential for all stakeholders within the specialty (e.g., patients, providers) to benefit from telehealth adoption. $[14,17,18]$

With the arrival of COVID-19, the healthcare industry has witnessed a massive acceleration in the use of telehealth, not only because of physical (social) distancing requirements, but also due to the temporary removal of policy \& regulatory barriers to telehealth access. [19] Nevertheless, the questions that do not yet have definitive answers are: Is telehealth here to stay? Will providers find it to be an effective method for providing care? Will patients prefer it over traditional in-person visits? Will policy barriers to telehealth 
access be permanently lifted? $[19,20]$ Although there is much uncertainty about the future of telehealth in the post-pandemic era, one point of consensus is that the elimination of policy barriers by itself, would not suffice to enable widespread, sustainable use of telehealth services. [6, 20] Instead, the telehealth literature has emphasized the need for providers and organizations to make concerted efforts to design and implement telehealth services for sustainable use. [20-23] Not surprisingly therefore, a growing stream of pandemic literature has emphasized the importance of addressing the challenge of wide variations in telehealth use, for ensuring widespread sustainability in the post-pandemic future. [24-27]

To be able to identify strategies for successful and sustainable telehealth use across all specialties in a post-pandemic era, it would be important to understand the "specialty-level factors" that historically influenced telehealth use among both "lower-using" specialties and "higher-using" specialties. To clarify, the term "telehealth use" in this paper, refers to adoption and utilization of telehealth services by providers (and patients) within a given medical specialty. Given the above background information, the two research questions are:

1. What specialty-level factors historically influenced telehealth use in six medical specialties, including three "higher-using" specialties (Cardiology, Psychiatry, Radiology) and three "lower-using" specialties (Allergy-Immunology, Gastroenterology, Family Medicine), in the US?

2. Which factors (barriers or facilitators) are associated with relatively lower telehealth use in some specialties and relatively higher telehealth use in other specialties?

By understanding the barriers to telehealth use among "lower-using" specialties and facilitators to telehealth use among "higher-using" specialties, we seek to identify strategies for reducing variation in telehealth use across all medical specialties, and discern implications for ensuring widespread, sustainable use of telehealth services in a post-pandemic environment.

\section{Purpose \& Aims}

In keeping with the research questions, the purpose of this paper is to conduct a systematic review and narrative synthesis of the literature to identify the key factors historically influencing telehealth use in six medical specialties (selected to represent a wide variation in historical telehealth use), including three "lower-using" specialties (Allergy-Immunology, Gastroenterology, and Family Medicine) and three "higherusing" specialties (Cardiology, Psychiatry, Radiology). The specific aims of the review are to:

1. Describe the factors (including barriers and facilitators) historically influencing telehealth use in six medical specialties in the US including three "lower-using" specialties and three "higher-using" specialties.

2. Identify strategies for reducing variation in telehealth use across medical specialties in a postpandemic era.

3. Discuss implications for ensuring widespread, sustainable telehealth use across medical specialties, in a post-pandemic era. 


\section{Methodology}

\section{Design}

We conducted a systematic review and narrative synthesis of the literature, using the guidance developed by Popay et al (2006), to examine factors historically influencing telehealth use across medical specialties. Narrative synthesis refers to 'an approach to the systematic review and synthesis of findings from multiple sources and relies primarily on the use of words and text to summarize and explain the findings of the synthesis.' $[28,29]$ It is used when statistical meta-analysis or another specialized form of synthesis (e.g., meta-ethnography for qualitative studies) is not feasible, due to high degrees of breadth and heterogeneity in the literature. Given our broad topic of interest, our literature of interest was also broad, including peer-reviewed original studies, reviews, specialty-society workgroup reports \& position statements. Our focus was to review all forms of peer-reviewed literature that helped to understand the factors that historically influenced telehealth use in each specialty.

\section{Data sources}

Article searches were conducted on the PUBMED database. Table 1 summarizes our search strategy. As indicated in the table, our initial database search entailed using key search terms ("Telehealth," "<Specialty Name>," "Barriers," "Facilitators") and closely-related terms informed by our conceptual framework (Fig. 1). PRISMA guidelines were used to inform the process of article selection based on study inclusion criteria (outlined below). [30] The PRISMA checklist is included in Appendix 1.

Table 1

Database Search Strategy

\begin{tabular}{|ll|}
\hline Key search terms & Closely-related terms \\
\hline Telehealth & Telemedicine \\
\hline Barriers, Facilitators & $\begin{array}{l}\text { Influencing factors, including macro (policy-level) } \\
\text { factors, meso (organizational-level) factors; and micro } \\
\text { (individual-level) factors. }\end{array}$ \\
$\begin{array}{l}\text { Specialty Name: Allergy-Immunology, } \\
\text { Gastroenterology, Family Medicine, } \\
\text { Cardiology, Psychiatry, Radiology. }\end{array}$ & $\begin{array}{l}\text { Specialty Name: Allergy, Hepatology, Primary Care, } \\
\text { Cardiovascular, Behavioral or Mental Health, Imaging. }\end{array}$ \\
\hline
\end{tabular}

\section{Developing a narrative synthesis}

We followed the steps delineated by Popay et al (2006), namely (1) Identifying a conceptual framework, (2) developing a preliminary synthesis (which included identifying inclusion \& exclusion criteria), (3) exploring themes in the data, and (4) assessing robustness of final synthesis [28]. We used the macromeso-micro three-layer framework (available since the beginnings of social science research), to guide our review. [31-33] This framework (Fig. 1), represents three layers of factors influencing behavior (e.g., 
telehealth use in a medical specialty). The macro layer represents factors at the societal level (e.g., policy or structura/ factors); the meso layer represents factors at a group level (e.g., organizational factors in a given medical specialty), and the micro layer represents factors at the individual level (e.g., provider-or patient-leve/ factors).The framework aims to capture three layers of factors as well as the interrelationships among those layers in influencing behavior. It also highlights the role of context in shaping interrelationships across the three layers, to ultimately influence behavior.

Ly et al (2017) used the macro-meso-micro framework to characterize the factors influencing telemedicine use in Senegal. [34] In their framework, the macro layer included political, financial, legal, and ethical, factors; the meso layer included organizational and technical factors; while the micro layer included individual intention to use telemedicine. This framework provided a starting point for a preliminary synthesis of the literature, which in turn enabled further refinement of the framework in regard to specialty-level factors of relevance to this review. The final conceptual framework used to guide the narrative synthesis, comprised of a total of 12 factors across the three layers, including 3 in the macro layer, 7 in the meso layer, and 2 in the micro layer. It is summarized in Fig. 1.

\section{Preliminary Synthesis (Inclusion \& Exclusion Criteria)}

As part of preliminary synthesis, articles resulting from the initial PUBMED database search were screened by the three authors who worked together to determine eligibility criteria for inclusion in the review. As mentioned earlier, all forms of peer-reviewed literature that helped to address the two research questions (e.g., original studies, reviews, specialty-society workgroup reports, position statements), were included. Since the interest was in understanding factors historically influencing telehealth use across medical specialties, the search was not restricted by date. On the other hand, in keeping with the scope of the review (within the US), articles that did not originate in the US were excluded. Additionally, articles with a narrow focus were excluded, for example, if they described specific results of telehealth-related outcomes research, e.g., for special populations or modalities. To clarify, since our primary research question was broad-to understand the factors historically influencing telehealth use across specialtiesit was more relevant to understand how many such studies (e.g., telehealth-related clinical trials) existed in a given specialty over a 10-year period preceding COVID-19 and to understand the state of telehealthrelated research in that specialty, rather than to know the specific results of such studies. The above exclusion criterion in turn, helped to add 'research factors' to our conceptual framework at the meso (specialty) level. Lastly, articles were excluded if they did not shed light on either research question, or if they duplicated the insights already gained.

\section{Data Extraction and Exploration of Themes for Final Narrative Synthesis}

Extraction of article descriptive characteristics: The following information was extracted from articles reviewed, for final synthesis: (1) article citation; 2 ) type of article; 3 ) layer of emphasis (macro, meso, or micro); 4) research question addressed; 5) descriptive summary of article. Extracted data was reviewed by all authors for disparities or inconsistencies. 
Generation of textual summary for exploration of themes: Next, the conceptual framework was used as a basis for exploring themes among articles within and across specialties, to address the two research questions. Articles within each specialty were reviewed for information pertaining to any of the 12 factors encompassed in the macro, meso, and micro layers. This process helped to generate a textual summary of articles within each specialty (for each of the 12 factors), which in turn, enabled exploration of themes within and across specialties. For details, please refer to "Research Protocol" in Appendix 2.

\section{Assessing the Robustness of Final Narrative Synthesis}

The textual summary of articles was maintained in a Microsoft Excel workbook. Each author maintained a separate workbook. All three authors independently reviewed included articles (in all six specialties) for final synthesis. Each individual workbook included six worksheets dedicated to each specialty of interest. In keeping with the conceptual framework, each worksheet was organized by layer and factor (for a total of 12 factors under the three layers). Each worksheet contained a textual summary for every factor in the cell block adjacent to the factor name. The robustness of final synthesis was assessed in three stages. $[28,35]$ In Stage 1, all three authors (Author-1, Author-2, and Author-3) independently reviewed all articles in each of the six specialties to develop textual summaries for each factor in each specialty worksheet. In Stage 2, the three authors met several times to discuss their respective textual summaries within each specialty, to enable identification of overlapping and distinct themes across the three author-pairs (Author-1 \& Author-2; Author-1 \& Author-3; Author-2 \& Author-3). During the course of these discussions, all overlapping themes were acknowledged, and distinct themes were verified through re-review of relevant articles. This process was repeated for all textual summaries in the six worksheets. For more details related to this process, please refer to "Research Protocol" in Appendix 2. In Stage 3, the first author developed an integrated workbook to include the worksheets from all three authors for every specialty. The first worksheet for every specialty was updated to include the number of overlapping and distinct themes relevant to each textual summary, for each author-pair. The integrated workbook, which constituted the "raw dataset" for final narrative synthesis, contained 18 worksheets ( 3 for each of the 6 specialties). It is included in Appendix 3.

\section{Results}

PRISMA guidelines were used to guide reporting of the literature reviewed. [30] A flowchart is shown in Fig. 2. A total of 8,376 records were available on PUBMED, related to telehealth or telemedicine across the six specialties of interest. The initial database search helped to identify a total of 221 articles of interest. After removal of duplicates, 163 article-abstracts were screened and articles were excluded if they did not originate in the US. The full-text of the remaining 107 articles was obtained to assess eligibility based on article scope, research questions, and duplication of insights. A final total of 53 articles were included for review and synthesis, including 8 articles in Allergy-Immunology, 10 in Gastroenterology, 8 in Family Medicine, 10 in Cardiology, 10 in Psychiatry, and 7 in Radiology. [36-88] Table 2 provides a descriptive summary of each article reviewed and Table 3 summarizes the theme-headings identified from final narrative synthesis. These themes are discussed below in greater detail. 
Table 2

Characteristics of 53 articles included in the review

\begin{tabular}{|c|c|c|c|c|c|}
\hline$\#$ & $\begin{array}{l}\text { Article } \\
\text { citation }\end{array}$ & Type of article & $\begin{array}{l}\text { Layer(s) } \\
\text { of } \\
\text { emphasis }\end{array}$ & $\begin{array}{l}\text { Research } \\
\text { question }\end{array}$ & Descriptive summary \\
\hline \multicolumn{6}{|c|}{ Allergy-Immunology } \\
\hline 1 & $\begin{array}{l}\text { Ref. } \\
\# 36\end{array}$ & Review & $\begin{array}{l}\text { Macro, } \\
\text { Meso, } \\
\text { Micro }\end{array}$ & $1 \& 2$ & $\begin{array}{l}\text { Describes how use of telemedicine, } \\
\text { when combined with information } \\
\text { technologies such as electronic health } \\
\text { records, has the potential to cause a } \\
\text { transformational change in the way } \\
\text { care is delivered in Allergy-Immunology. }\end{array}$ \\
\hline 2 & $\begin{array}{l}\text { Ref. } \\
\# 37\end{array}$ & $\begin{array}{l}\text { Work Group } \\
\text { Report }\end{array}$ & $\begin{array}{l}\text { Macro, } \\
\text { Meso, } \\
\text { Micro }\end{array}$ & $1 \& 2$ & $\begin{array}{l}\text { Members of the Telemedicine Work } \\
\text { Group in the AAAAl completed a } \\
\text { telemedicine literature review of online } \\
\text { and Pub Med resources through May } \\
2020 \text {, to detail Pre-COVID-19 } \\
\text { telemedicine knowledge and outline up- } \\
\text { to-date telemedicine material. This } \\
\text { work group report was developed to } \\
\text { provide guidance to } \\
\text { allergy/immunology clinicians as they } \\
\text { navigate the swiftly evolving } \\
\text { telemedicine landscape. }\end{array}$ \\
\hline 3 & $\begin{array}{l}\text { Ref. } \\
\# 38\end{array}$ & $\begin{array}{l}\text { Controlled } \\
\text { Clinical Trial }\end{array}$ & $\begin{array}{l}\text { Meso, } \\
\text { Micro }\end{array}$ & 1 & $\begin{array}{l}\text { Children with asthma seen by } \\
\text { telemedicine or in-person visits can } \\
\text { achieve comparable degrees of asthma } \\
\text { control. Telemedicine can be a viable } \\
\text { alternative to traditional in-person } \\
\text { physician-based care for the treatment } \\
\text { and management of asthma. }\end{array}$ \\
\hline 4 & $\begin{array}{l}\text { Ref. } \\
\# 39\end{array}$ & $\begin{array}{l}\text { Position } \\
\text { Statement }\end{array}$ & $\begin{array}{l}\text { Macro, } \\
\text { Meso, } \\
\text { Micro }\end{array}$ & $1 \& 2$ & $\begin{array}{l}\text { Potential benefits of telemedicine } \\
\text { should be weighed against the risks } \\
\text { and challenges of using telemedicine. } \\
\text { This article serves to offer policy and } \\
\text { position statements of the use of } \\
\text { telemedicine pertinent to the allergy } \\
\text { and immunology subspecialty. }\end{array}$ \\
\hline 5 & $\begin{array}{l}\text { Ref. } \\
\# 40\end{array}$ & Meta-Analysis & $\begin{array}{l}\text { Meso, } \\
\text { Micro }\end{array}$ & 1 & $\begin{array}{l}\text { Combined-telemedicine involving tele- } \\
\text { case management or tele-consultation } \\
\text { are effective in improving asthma } \\
\text { control and quality of life in adults. The } \\
\text { findings provide health care } \\
\text { professionals with current evidence of } \\
\text { the effects of telemedicine on asthma } \\
\text { control and patients' quality of life. }\end{array}$ \\
\hline
\end{tabular}




\begin{tabular}{|c|c|c|c|c|c|}
\hline$\#$ & $\begin{array}{l}\text { Article } \\
\text { citation }\end{array}$ & Type of article & $\begin{array}{l}\text { Layer(s) } \\
\text { of } \\
\text { emphasis }\end{array}$ & $\begin{array}{l}\text { Research } \\
\text { question }\end{array}$ & Descriptive summary \\
\hline 6 & $\begin{array}{l}\text { Ref. } \\
\# 41\end{array}$ & Review & Micro & $1 \& 2$ & $\begin{array}{l}\text { Providers tend to be satisfied with } \\
\text { telemedicine if they have input into its } \\
\text { development, there is administrative } \\
\text { support, the technology is reliable and } \\
\text { easy to use, and if there is adequate } \\
\text { reimbursement for its use. Satisfaction } \\
\text { with telemedicine is necessary for } \\
\text { adoption of this new technology. To } \\
\text { improve satisfaction it is important to } \\
\text { consider factors that drive it both for } \\
\text { patients and for providers. }\end{array}$ \\
\hline 7 & $\begin{array}{l}\text { Ref. } \\
\# 42\end{array}$ & Review & Micro & 1 & $\begin{array}{l}\text { Discusses how telemedicine and } \\
\text { telehealth technologies can be used to } \\
\text { strengthen medical services and } \\
\text { overcome many of the barriers that } \\
\text { have previously existed by providing } \\
\text { safe, accessible, cost-effective, and } \\
\text { convenient health care at the touch of } \\
\text { a button. }\end{array}$ \\
\hline 8 & $\begin{array}{l}\text { Ref. } \\
\# 43\end{array}$ & Review & Micro & $1 \& 2$ & $\begin{array}{l}\text { Discusses how with utilization of } \\
\text { digital exam equipment, in vitro tests } \\
\text { for diagnosis, and spirometry at the } \\
\text { patient location, there are few clear } \\
\text { advantages of seeing patients' in- } \\
\text { person over virtual visits. Telemedicine } \\
\text { is here today. As its use increases, it is } \\
\text { critical that allergy specialists embrace } \\
\text { this new technology. }\end{array}$ \\
\hline \multicolumn{6}{|c|}{ Gastroenterology } \\
\hline 9 & $\begin{array}{l}\text { Ref. } \\
\# 44\end{array}$ & Review & $\begin{array}{l}\text { Macro, } \\
\text { Meso, } \\
\text { Micro }\end{array}$ & $1 \& 2$ & $\begin{array}{l}\text { Explores the rationale behind initial } \\
\text { construction of value-based IBD } \\
\text { specialty medical homes, the critical } \\
\text { personnel and components, the early } \\
\text { outcomes of established models, } \\
\text { comparison with other value-based } \\
\text { care models, and the role of an IBD } \\
\text { SMH in population health } \\
\text { management. }\end{array}$ \\
\hline 10 & $\begin{array}{l}\text { Ref. } \\
\# 45\end{array}$ & Review & $\begin{array}{l}\text { Macro, } \\
\text { Meso, } \\
\text { Micro }\end{array}$ & $1 \& 2$ & $\begin{array}{l}\text { The future of value-based care in IBD is } \\
\text { bright, with ample opportunities for } \\
\text { growth. }\end{array}$ \\
\hline 11 & $\begin{array}{l}\text { Ref. } \\
\# 46\end{array}$ & Clinical Review & $\begin{array}{l}\text { Meso, } \\
\text { Micro }\end{array}$ & 1 & $\begin{array}{l}\text { Describes how the IBD specialty } \\
\text { medical home was constructed and } \\
\text { implemented at the University of } \\
\text { Pittsburgh Medical Center (UPMC). }\end{array}$ \\
\hline
\end{tabular}




\begin{tabular}{|c|c|c|c|c|c|}
\hline \# & $\begin{array}{l}\text { Article } \\
\text { citation }\end{array}$ & Type of article & $\begin{array}{l}\text { Layer(s) } \\
\text { of } \\
\text { emphasis }\end{array}$ & $\begin{array}{l}\text { Research } \\
\text { question }\end{array}$ & Descriptive summary \\
\hline 12 & $\begin{array}{l}\text { Ref. } \\
\# 47\end{array}$ & Meta-Analysis & $\begin{array}{l}\text { Meso, } \\
\text { Micro }\end{array}$ & 1 & $\begin{array}{l}\text { A systematic review and meta-analysis } \\
\text { of randomized controlled trials } \\
\text { comparing distance management and } \\
\text { standard clinic follow-up in the } \\
\text { management of adult IBD patients. The } \\
\text { review found that distance } \\
\text { management of IBD significantly } \\
\text { decreases clinic visit utilization. }\end{array}$ \\
\hline 13 & $\begin{array}{l}\text { Ref. } \\
\# 48\end{array}$ & $\begin{array}{l}\text { Rapid } \\
\text { Communication }\end{array}$ & $\begin{array}{l}\text { Macro, } \\
\text { Meso, } \\
\text { Micro }\end{array}$ & 1 & $\begin{array}{l}\text { This communication article from field } \\
\text { leaders during the pandemic, discusses } \\
\text { best practice recommendations for } \\
\text { introducing and expanding telehealth } \\
\text { in pediatric gastroenterology. }\end{array}$ \\
\hline 14 & $\begin{array}{l}\text { Ref. } \\
\# 49\end{array}$ & $\begin{array}{l}\text { Program } \\
\text { Review }\end{array}$ & $\begin{array}{l}\text { Meso, } \\
\text { Micro }\end{array}$ & $1 \& 2$ & $\begin{array}{l}\text { This program review discusses a } \\
\text { specialty outreach program which } \\
\text { relied on telemedicine to reach patients } \\
\text { with gastrointestinal and liver diseases } \\
\text { in a large service area. }\end{array}$ \\
\hline 15 & $\begin{array}{l}\text { Ref. } \\
\# 50\end{array}$ & $\begin{array}{l}\text { Future } \\
\text { Directions }\end{array}$ & $\begin{array}{l}\text { Macro, } \\
\text { Meso, } \\
\text { Micro }\end{array}$ & $1 \& 2$ & $\begin{array}{l}\text { Prior to } 2000 \text {, a typical community GI } \\
\text { practice comprised } 1 \text { to } 8 \text { physicians. } \\
\text { This article describes } 5 \text { new models of } \\
\text { practice that have emerged in the past } \\
\text { decade and have become viable } \\
\text { choices for beginning and seasoned } \\
\text { gastroenterologists alike. }\end{array}$ \\
\hline 16 & $\begin{array}{l}\text { Ref. } \\
\# 51\end{array}$ & $\begin{array}{l}\text { Original } \\
\text { Research }\end{array}$ & $\begin{array}{l}\text { Meso, } \\
\text { Micro }\end{array}$ & 1 & $\begin{array}{l}\text { Reports on the results of a survey of GI } \\
\text { patients' and physicians' satisfaction } \\
\text { with telehealth during the COVID-19 } \\
\text { pandemic. The results showed high } \\
\text { satisfaction and acceptance with } \\
\text { virtual encounters. }\end{array}$ \\
\hline 17 & $\begin{array}{l}\text { Ref. } \\
\# 52\end{array}$ & Review & $\begin{array}{l}\text { Meso, } \\
\text { Micro }\end{array}$ & $1 \& 2$ & $\begin{array}{l}\text { The use of telehealth video conference } \\
\text { and remote patient monitoring with } \\
\text { web-based applications and text } \\
\text { messaging in IBD care has been shown } \\
\text { to ease financial burdens of chronic } \\
\text { disease, improve patient quality of life, } \\
\text { and lead to improved clinical } \\
\text { outcomes. }\end{array}$ \\
\hline
\end{tabular}




\begin{tabular}{|c|c|c|c|c|c|}
\hline \# & $\begin{array}{l}\text { Article } \\
\text { citation }\end{array}$ & Type of article & $\begin{array}{l}\text { Layer(s) } \\
\text { of } \\
\text { emphasis }\end{array}$ & $\begin{array}{l}\text { Research } \\
\text { question }\end{array}$ & Descriptive summary \\
\hline 18 & $\begin{array}{l}\text { Ref. } \\
\# 53\end{array}$ & Review & $\begin{array}{l}\text { Macro, } \\
\text { Meso, } \\
\text { Micro }\end{array}$ & $1 \& 2$ & $\begin{array}{l}\text { Gastroenterologists need to rapidly } \\
\text { adapt to the challenges being faced } \\
\text { and need to make both systems and } \\
\text { practice-based changes to the } \\
\text { endoscopy unit and outpatient clinic } \\
\text { practices. Separate from the } \\
\text { management of COVID-19 patients, } \\
\text { there has been a reduction in } \\
\text { endoscopy volume. This has also } \\
\text { resulted in reduction of in-person clinic } \\
\text { visits and an increasing use of } \\
\text { telemedicine services. }\end{array}$ \\
\hline \multicolumn{6}{|c|}{ Family Medicine } \\
\hline 19 & $\begin{array}{l}\text { Ref. } \\
\# 54\end{array}$ & $\begin{array}{l}\text { Original } \\
\text { Research }\end{array}$ & $\begin{array}{l}\text { Meso, } \\
\text { Micro }\end{array}$ & $1 \& 2$ & $\begin{array}{l}\text { This study found telehealth use was } \\
\text { limited among family physicians. Lack } \\
\text { of training for telehealth and lack of } \\
\text { reimbursement were found to be key } \\
\text { barriers to telehealth use. }\end{array}$ \\
\hline 20 & $\begin{array}{l}\text { Ref. } \\
\# 55\end{array}$ & $\begin{array}{l}\text { Original } \\
\text { Research }\end{array}$ & $\begin{array}{l}\text { Meso, } \\
\text { Micro }\end{array}$ & 1 & $\begin{array}{l}\text { Primary care video visits are } \\
\text { acceptable in a variety of situations. } \\
\text { Patients identified convenience, } \\
\text { efficiency, communication, privacy, and } \\
\text { comfort as domains that are } \\
\text { potentially important to consider when } \\
\text { assessing video visits vs in-person } \\
\text { encounters. }\end{array}$ \\
\hline 21 & $\begin{array}{l}\text { Ref. } \\
\# 56\end{array}$ & $\begin{array}{l}\text { Rapid } \\
\text { Communication }\end{array}$ & $\begin{array}{l}\text { Macro, } \\
\text { Meso, } \\
\text { Micro }\end{array}$ & $1 \& 2$ & $\begin{array}{l}\text { Throughout the pandemic, primary care } \\
\text { practices bore tremendous financial } \\
\text { burden, laying off staff or even closing } \\
\text { at a time when most needed. Primary } \\
\text { care must learn from this experience } \\
\text { and be ready for the next pandemic. }\end{array}$ \\
\hline 22 & $\begin{array}{l}\text { Ref. } \\
\# 57\end{array}$ & $\begin{array}{l}\text { Randomized } \\
\text { Controlled Trial }\end{array}$ & $\begin{array}{l}\text { Meso, } \\
\text { Micro }\end{array}$ & 1 & $\begin{array}{l}\text { Telehealth can improve transitions of } \\
\text { care after hospital discharge improving } \\
\text { patient engagement and adherence to } \\
\text { medications. Additional research is } \\
\text { needed to understand the true impact } \\
\text { of Telehealth on preventing avoidable } \\
\text { hospital readmission and emergency } \\
\text { department visits. }\end{array}$ \\
\hline 23 & $\begin{array}{l}\text { Ref. } \\
\# 58\end{array}$ & Review & $\begin{array}{l}\text { Macro, } \\
\text { Meso, } \\
\text { Micro }\end{array}$ & $1 \& 2$ & $\begin{array}{l}\text { This paper explores primary care health } \\
\text { IT deployment to date, its } \\
\text { shortcomings in support of the nation's } \\
\text { Triple Aim, and offers strategies and } \\
\text { tactics that family medicine could } \\
\text { pursue to improve the utility of health } \\
\text { IT for primary care. }\end{array}$ \\
\hline
\end{tabular}




\begin{tabular}{|c|c|c|c|c|c|}
\hline$\#$ & $\begin{array}{l}\text { Article } \\
\text { citation }\end{array}$ & Type of article & $\begin{array}{l}\text { Layer(s) } \\
\text { of } \\
\text { emphasis }\end{array}$ & $\begin{array}{l}\text { Research } \\
\text { question }\end{array}$ & Descriptive summary \\
\hline 24 & $\begin{array}{l}\text { Ref. } \\
\# 59\end{array}$ & $\begin{array}{l}\text { Original } \\
\text { Research }\end{array}$ & $\begin{array}{l}\text { Macro, } \\
\text { Meso, } \\
\text { Micro }\end{array}$ & $1 \& 2$ & $\begin{array}{l}\text { Systemwide changes will be needed to } \\
\text { ensure high-quality health care for all } \\
\text { Americans. Such changes include } \\
\text { taking steps to ensure that every } \\
\text { American has a personal medical } \\
\text { home, promoting the use and reporting } \\
\text { of quality measures to improve } \\
\text { performance and service. }\end{array}$ \\
\hline 25 & $\begin{array}{l}\text { Ref. } \\
\# 60\end{array}$ & $\begin{array}{l}\text { Rapid } \\
\text { Communication }\end{array}$ & $\begin{array}{l}\text { Macro, } \\
\text { Meso }\end{array}$ & $1 \& 2$ & $\begin{array}{l}\text { Discusses how the [pandemic] has } \\
\text { accelerated the closure of many family } \\
\text { practices. }\end{array}$ \\
\hline 26 & $\begin{array}{l}\text { Ref. } \\
\# 61\end{array}$ & $\begin{array}{l}\text { Randomized } \\
\text { Controlled Trial }\end{array}$ & $\begin{array}{l}\text { Meso, } \\
\text { Micro }\end{array}$ & 1 & $\begin{array}{l}\text { The addition of technology alone is } \\
\text { unlikely to lead to improvements in } \\
\text { outcomes. Practices need to be } \\
\text { selective in their use of telemonitoring } \\
\text { with patients, limiting it to patients who } \\
\text { have motivation or a significant } \\
\text { change in care, such as starting insulin. }\end{array}$ \\
\hline \multicolumn{6}{|c|}{ Cardiology } \\
\hline 27 & $\begin{array}{l}\text { Ref. } \\
\# 62\end{array}$ & Review & $\begin{array}{l}\text { Macro, } \\
\text { Meso, } \\
\text { Micro }\end{array}$ & $1 \& 2$ & $\begin{array}{l}\text { Increasingly, cardiologists across the } \\
\text { country are leveraging technology to } \\
\text { provide remote care, whether through } \\
\text { virtual visits and exams, consultations, } \\
\text { or continuous monitoring using a } \\
\text { growing array of implantable or } \\
\text { wearable devices. }\end{array}$ \\
\hline 28 & $\begin{array}{l}\text { Ref. } \\
\# 63\end{array}$ & $\begin{array}{l}\text { Randomized } \\
\text { Controlled Trial }\end{array}$ & $\begin{array}{l}\text { Meso, } \\
\text { Micro }\end{array}$ & 1 & $\begin{array}{l}\text { Telehealth medication adherence } \\
\text { technologies are a promising method } \\
\text { to improve patient self-management, } \\
\text { the quality of patient care, and reduce } \\
\text { health care utilization and expenditure } \\
\text { for patients with heart failure and other } \\
\text { chronic diseases that require complex } \\
\text { medication regimens. }\end{array}$ \\
\hline 29 & $\begin{array}{l}\text { Ref. } \\
\# 64\end{array}$ & Review & $\begin{array}{l}\text { Meso, } \\
\text { Micro }\end{array}$ & 1 & $\begin{array}{l}\text { In light of the current pandemic, } \\
\text { monitoring strategies should focus on } \\
\text { selecting high-risk patients in need of } \\
\text { close surveillance and using alternative } \\
\text { remote recording devices to preserve } \\
\text { personal protective equipment and } \\
\text { protect healthcare workers from } \\
\text { potential contagious harm. }\end{array}$ \\
\hline
\end{tabular}




\begin{tabular}{|c|c|c|c|c|c|}
\hline$\#$ & $\begin{array}{l}\text { Article } \\
\text { citation }\end{array}$ & Type of article & $\begin{array}{l}\text { Layer(s) } \\
\text { of } \\
\text { emphasis }\end{array}$ & $\begin{array}{l}\text { Research } \\
\text { question }\end{array}$ & Descriptive summary \\
\hline 30 & $\begin{array}{l}\text { Ref. } \\
\# 65\end{array}$ & $\begin{array}{l}\text { Policy } \\
\text { Statement }\end{array}$ & $\begin{array}{l}\text { Meso, } \\
\text { Micro }\end{array}$ & $1 \& 2$ & $\begin{array}{l}\text { Evaluates the effectiveness of } \\
\text { telehealth in advancing healthcare } \\
\text { quality, identifies legal and regulatory } \\
\text { barriers that impede telehealth } \\
\text { adoption or delivery, propose steps to } \\
\text { overcome these barriers, and identifies } \\
\text { areas for future research to ensure that } \\
\text { telehealth continues to enhance the } \\
\text { quality of cardiovascular and stroke } \\
\text { care. }\end{array}$ \\
\hline 31 & $\begin{array}{l}\text { Ref. } \\
\# 66\end{array}$ & $\begin{array}{l}\text { Scientific } \\
\text { Statement }\end{array}$ & $\begin{array}{l}\text { Macro, } \\
\text { Meso, } \\
\text { Micro }\end{array}$ & $1 \& 2$ & $\begin{array}{l}\text { Although there are many nuances to } \\
\text { the relationships between self-care and } \\
\text { outcomes, there is strong evidence that } \\
\text { self-care is effective in achieving the } \\
\text { goals of the treatment plan and cannot } \\
\text { be ignored. As such, greater emphasis } \\
\text { should be placed on self-care in } \\
\text { evidence-based guidelines. }\end{array}$ \\
\hline 32 & $\begin{array}{l}\text { Ref. } \\
\# 67\end{array}$ & Review & $\begin{array}{l}\text { Meso, } \\
\text { Micro }\end{array}$ & 1 & $\begin{array}{l}\text { The use of adapted staffing and billing } \\
\text { models and expanded means of } \\
\text { remote monitoring will aid in the } \\
\text { incorporation of telehealth into more } \\
\text { widespread pediatric cardiology } \\
\text { practice. Future directions to sustain } \\
\text { this platform include the refinement of } \\
\text { telehealth care strategies, defining best } \\
\text { practices, including telehealth in the } \\
\text { fellowship curriculum and continuing } \\
\text { advocacy for technology. }\end{array}$ \\
\hline 33 & $\begin{array}{l}\text { Ref. } \\
\# 68\end{array}$ & Review & $\begin{array}{l}\text { Meso, } \\
\text { Micro }\end{array}$ & 1 & $\begin{array}{l}\text { Multidisciplinary intervention resulted } \\
\text { in decreased all-cause readmission and } \\
\text { congestive heart failure readmission. } \\
\text { There was some discrepancy on } \\
\text { effectiveness of tele-monitoring } \\
\text { programs in individual studies; } \\
\text { however, meta-analyses suggest tele- } \\
\text { monitoring provided reduced all-cause } \\
\text { mortality and risk of congestive heart } \\
\text { failure hospitalization. }\end{array}$ \\
\hline
\end{tabular}




\begin{tabular}{|c|c|c|c|c|c|}
\hline$\#$ & $\begin{array}{l}\text { Article } \\
\text { citation }\end{array}$ & Type of article & $\begin{array}{l}\text { Layer(s) } \\
\text { of } \\
\text { emphasis }\end{array}$ & $\begin{array}{l}\text { Research } \\
\text { question }\end{array}$ & Descriptive summary \\
\hline 34 & $\begin{array}{l}\text { Ref. } \\
\# 69\end{array}$ & Review & $\begin{array}{l}\text { Meso, } \\
\text { Micro }\end{array}$ & $1 \& 2$ & $\begin{array}{l}\text { The evidence is organized and } \\
\text { presented within the context of the } \\
\text { American Heart Association's Stroke } \\
\text { Systems of Care framework and is } \\
\text { classified according to the joint } \\
\text { American Heart Association/American } \\
\text { College of Cardiology Foundation and } \\
\text { supplementary American Heart } \\
\text { Association Stroke Council methods of } \\
\text { classifying the level of certainty and } \\
\text { the class of evidence. Evidence-based } \\
\text { recommendations are included for } \\
\text { various levels of care. }\end{array}$ \\
\hline 35 & $\begin{array}{l}\text { Ref. } \\
\# 70\end{array}$ & Review & $\begin{array}{l}\text { Meso, } \\
\text { Micro }\end{array}$ & $1 \& 2$ & $\begin{array}{l}\text { With the growing prevalence of } \\
\text { cardiopulmonary disease, mHealth } \\
\text { technologies may become a more } \\
\text { essential element of care within and } \\
\text { outside of traditional health-care } \\
\text { settings. mHealth is continuously } \\
\text { developing as a result of technologic } \\
\text { advancements and better } \\
\text { understandings of mHealth utility. }\end{array}$ \\
\hline 36 & $\begin{array}{l}\text { Ref. } \\
\# 71\end{array}$ & $\begin{array}{l}\text { Original } \\
\text { Research }\end{array}$ & $\begin{array}{l}\text { Meso, } \\
\text { Micro }\end{array}$ & 1 & $\begin{array}{l}\text { A navigator-led remote management } \\
\text { strategy for optimization of guideline } \\
\text { directed medical therapy may represent } \\
\text { a scalable population-level strategy for } \\
\text { closing the gap between guidelines and } \\
\text { clinical practice in patients with heart } \\
\text { failure with reduced ejection fraction. }\end{array}$ \\
\hline \multicolumn{6}{|c|}{ Psychiatry } \\
\hline 37 & $\begin{array}{l}\text { Ref. } \\
\# 72\end{array}$ & $\begin{array}{l}\text { Original } \\
\text { Research }\end{array}$ & $\begin{array}{l}\text { Macro, } \\
\text { Meso, } \\
\text { Micro }\end{array}$ & $1 \& 2$ & $\begin{array}{l}\text { Telepsychiatry and improvements in } \\
\text { training of the mental health workforce } \\
\text { are listed as useful implementations to } \\
\text { overcome the treatment gap for } \\
\text { patients seeking mental health care. }\end{array}$ \\
\hline 38 & $\begin{array}{l}\text { Ref. } \\
\# 73\end{array}$ & $\begin{array}{l}\text { Practice } \\
\text { Guidelines }\end{array}$ & $\begin{array}{l}\text { Meso, } \\
\text { Micro }\end{array}$ & $1 \& 2$ & $\begin{array}{l}\text { This guideline document discusses } \\
\text { guidelines ATA for the practices of } \\
\text { telemental health and applications for } \\
\text { the practice of telemedicine in clinical } \\
\text { psychiatry. }\end{array}$ \\
\hline 39 & $\begin{array}{l}\text { Ref. } \\
\# 74\end{array}$ & $\begin{array}{l}\text { Workgroup } \\
\text { Report }\end{array}$ & $\begin{array}{l}\text { Meso, } \\
\text { Micro }\end{array}$ & $1 \& 2$ & $\begin{array}{l}\text { This article updates and consolidates } \\
\text { guidance developed by The American } \\
\text { Telemedicine Association (ATA) and } \\
\text { The American Psychiatric Association } \\
\text { (APA) on the development, } \\
\text { implementation, administration, and } \\
\text { provision of telemental health services. }\end{array}$ \\
\hline
\end{tabular}




\begin{tabular}{|c|c|c|c|c|c|}
\hline$\#$ & $\begin{array}{l}\text { Article } \\
\text { citation }\end{array}$ & Type of article & $\begin{array}{l}\text { Layer(s) } \\
\text { of } \\
\text { emphasis }\end{array}$ & $\begin{array}{l}\text { Research } \\
\text { question }\end{array}$ & Descriptive summary \\
\hline 40 & $\begin{array}{l}\text { Ref. } \\
\# 75\end{array}$ & $\begin{array}{l}\text { Randomized } \\
\text { Controlled Trial }\end{array}$ & $\begin{array}{l}\text { Meso, } \\
\text { Micro }\end{array}$ & 1 & $\begin{array}{l}\text { This study examined whether patients } \\
\text { who had been nonadherent with } \\
\text { outpatient appointments and who were } \\
\text { randomly assigned to receive treatment } \\
\text { through a telepsychiatry would show } \\
\text { improvement in adherence to } \\
\text { appointments. A greater number of } \\
\text { participants in the telepsychiatry group } \\
\text { reported less subjective difficulty in } \\
\text { keeping appointments. }\end{array}$ \\
\hline 41 & $\begin{array}{l}\text { Ref. } \\
\# 76\end{array}$ & $\begin{array}{l}\text { Randomized } \\
\text { Controlled Trial }\end{array}$ & $\begin{array}{l}\text { Meso, } \\
\text { Micro }\end{array}$ & 1 & $\begin{array}{l}\text { Describes a 5-year clinical trial } \\
\text { comparing asynchronous } \\
\text { telepsychiatry (ATP) with synchronous } \\
\text { telepsychiatry (STP) consultations was } \\
\text { consulted. Findings suggest that } \\
\text { implementing ATP in existing } \\
\text { integrated behavioral healthcare } \\
\text { models could make mental healthcare } \\
\text { more efficient. }\end{array}$ \\
\hline 42 & $\begin{array}{l}\text { Ref. } \\
\# 77\end{array}$ & $\begin{array}{l}\text { Randomized } \\
\text { Controlled Trial }\end{array}$ & $\begin{array}{l}\text { Meso, } \\
\text { Micro }\end{array}$ & 1 & $\begin{array}{l}\text { Results suggest that prolonged } \\
\text { exposure can be delivered via home- } \\
\text { based telehealth with outcomes and } \\
\text { satisfaction ratings comparable to in- } \\
\text { person practices for certain symptoms. } \\
\text { This modality has the potential to } \\
\text { address stigma- and geographic- } \\
\text { related barriers to treatment, such as } \\
\text { travel time and cost. }\end{array}$ \\
\hline 43 & $\begin{array}{l}\text { Ref. } \\
\# 78\end{array}$ & $\begin{array}{l}\text { Systematic } \\
\text { Review }\end{array}$ & $\begin{array}{l}\text { Macro, } \\
\text { Meso, } \\
\text { Micro }\end{array}$ & $1 \& 2$ & $\begin{array}{l}\text { A large evidence base supports } \\
\text { telepsychiatry as a delivery method for } \\
\text { mental health services. Future studies } \\
\text { will inform optimal approaches to } \\
\text { implementing and sustaining } \\
\text { telepsychiatry services. }\end{array}$ \\
\hline 44 & $\begin{array}{l}\text { Ref. } \\
\# 79\end{array}$ & Review & $\begin{array}{l}\text { Macro, } \\
\text { Meso, } \\
\text { Micro }\end{array}$ & $1 \& 2$ & $\begin{array}{l}\text { The review of the evidence broadly } \\
\text { covers mental health service provision } \\
\text { in all settings, including forensic } \\
\text { settings. It discusses implications for } \\
\text { mental health care across settings and } \\
\text { populations and comment on future } \\
\text { directions and potential uses in } \\
\text { forensic or correctional psychiatry. }\end{array}$ \\
\hline 45 & $\begin{array}{l}\text { Ref. } \\
\# 80\end{array}$ & $\begin{array}{l}\text { Original } \\
\text { Research }\end{array}$ & $\begin{array}{l}\text { Macro, } \\
\text { Meso }\end{array}$ & 1 & $\begin{array}{l}\text { While addressing the opioid crisis will } \\
\text { require multifaceted efforts involving } \\
\text { multiple stakeholders and different } \\
\text { approaches, a comprehensive strategy } \\
\text { must incorporate the adoption of } \\
\text { telepsychiatry to overcoming barriers to } \\
\text { treatment and enhancing access to } \\
\text { care. }\end{array}$ \\
\hline
\end{tabular}




\begin{tabular}{|c|c|c|c|c|c|}
\hline \# & $\begin{array}{l}\text { Article } \\
\text { citation }\end{array}$ & Type of article & $\begin{array}{l}\text { Layer(s) } \\
\text { of } \\
\text { emphasis }\end{array}$ & $\begin{array}{l}\text { Research } \\
\text { question }\end{array}$ & Descriptive summary \\
\hline 46 & $\begin{array}{l}\text { Ref. } \\
\# 81\end{array}$ & $\begin{array}{l}\text { Original } \\
\text { Research }\end{array}$ & $\begin{array}{l}\text { Meso, } \\
\text { Micro }\end{array}$ & $1 \& 2$ & $\begin{array}{l}\text { The coronavirus (COVID-19) pandemic } \\
\text { forced a sudden shift from traditional } \\
\text { in-person visits to alternative } \\
\text { modalities. This paper describes the } \\
\text { experience of a large health care } \\
\text { system using telehealth technology, } \\
\text { identifies strategies and discuss } \\
\text { considerations for long-term } \\
\text { sustainability after the pandemic. }\end{array}$ \\
\hline \multicolumn{6}{|c|}{ Radiology } \\
\hline 47 & $\begin{array}{l}\text { Ref. } \\
\# 82\end{array}$ & $\begin{array}{l}\text { Systematic } \\
\text { Review }\end{array}$ & $\begin{array}{l}\text { Macro, } \\
\text { Meso } \\
\text { Micro }\end{array}$ & $1 \& 2$ & $\begin{array}{l}\text { The evidence regarding feasibility of } \\
\text { teleradiology and related information } \\
\text { technology applications has been well } \\
\text { documented for several decades. A } \\
\text { consistent trend of concordance } \\
\text { between the two modalities } \\
\text { (teleradiology and conventional } \\
\text { radiology) was observed in terms of } \\
\text { diagnostic accuracy and reliability. } \\
\text { Additional benefits include reductions } \\
\text { in patient transfer, rehospitalization, } \\
\text { and length of stay. }\end{array}$ \\
\hline 48 & $\begin{array}{l}\text { Ref. } \\
\# 83\end{array}$ & $\begin{array}{l}\text { Original } \\
\text { Research }\end{array}$ & $\begin{array}{l}\text { Meso, } \\
\text { Micro }\end{array}$ & 1 & $\begin{array}{l}\text { In } 1998 \text { we surveyed our radiologists } \\
\text { on teleradiology satisfaction. Results } \\
\text { were generally positive. In } 2002 \text { we } \\
\text { experienced a sevenfold case increase } \\
\text { in teleradiology volume. The present } \\
\text { study surveyed the radiologists again. } \\
\text { Overall, the radiologists are satisfied, } \\
\text { although some improvements can be } \\
\text { made. }\end{array}$ \\
\hline 49 & $\begin{array}{l}\text { Ref. } \\
\# 84\end{array}$ & $\begin{array}{l}\text { Position } \\
\text { Statement }\end{array}$ & $\begin{array}{l}\text { Meso, } \\
\text { Micro }\end{array}$ & 1 & $\begin{array}{l}\text { Radiology practices should be aware of } \\
\text { the common approaches and } \\
\text { preparations academic radiology } \\
\text { departments have taken to reopening } \\
\text { imaging in the POST-coronavirus } \\
\text { disease } 2019 \text { world. This should all be } \\
\text { done when maintaining a safe and } \\
\text { patient-centric environment and } \\
\text { preparing to minimize the impact of } \\
\text { future outbreaks or pandemics. }\end{array}$ \\
\hline 50 & $\begin{array}{l}\text { Ref. } \\
\# 85\end{array}$ & Review & $\begin{array}{l}\text { Macro, } \\
\text { Meso } \\
\text { Micro }\end{array}$ & $1 \& 2$ & $\begin{array}{l}\text { This review aims to provide a } \\
\text { background history to the current } \\
\text { teleradiology services provided. It also } \\
\text { addresses the limitations and issues } \\
\text { involved in organizing such a service. }\end{array}$ \\
\hline
\end{tabular}




\begin{tabular}{|c|c|c|c|c|c|}
\hline \# & $\begin{array}{l}\text { Article } \\
\text { citation }\end{array}$ & Type of article & $\begin{array}{l}\text { Layer(s) } \\
\text { of } \\
\text { emphasis }\end{array}$ & $\begin{array}{l}\text { Research } \\
\text { question }\end{array}$ & Descriptive summary \\
\hline 51 & $\begin{array}{l}\text { Ref. } \\
\# 86\end{array}$ & $\begin{array}{l}\text { Rapid } \\
\text { Communication }\end{array}$ & $\begin{array}{l}\text { Meso, } \\
\text { Micro }\end{array}$ & $1 \& 2$ & $\begin{array}{l}\text { Describes the implementation of a } \\
\text { response plan in an academic } \\
\text { radiology department DURING COVID- } \\
19 \text {, challenges encountered, and tactics } \\
\text { used to address these challenges. }\end{array}$ \\
\hline 52 & $\begin{array}{l}\text { Ref. } \\
\# 87\end{array}$ & Review & $\begin{array}{l}\text { Macro, } \\
\text { Meso, } \\
\text { Micro }\end{array}$ & $1 \& 2$ & $\begin{array}{l}\text { Modern financial structures provide } \\
\text { radiologists with both entrepreneurial } \\
\text { opportunities as well as the temptation } \\
\text { for unprofessional conduct. Each of } \\
\text { these advances carries the potential for } \\
\text { professional growth while testing the } \\
\text { professional stature of radiology. By } \\
\text { considering the risks and benefits of } \\
\text { emerging technologies in the modern } \\
\text { radiology world, radiologists can chart } \\
\text { an ethical and professional future path. }\end{array}$ \\
\hline 53 & $\begin{array}{l}\text { Ref. } \\
\# 88\end{array}$ & Review & $\begin{array}{l}\text { Macro, } \\
\text { Meso, } \\
\text { Micro }\end{array}$ & $1 \& 2$ & $\begin{array}{l}\text { As the assault on the growth of } \\
\text { Medicare spending continues, with } \\
\text { medical imaging as a highly visible } \\
\text { target, radiologists must adapt to the } \\
\text { changing landscape by focusing on } \\
\text { their most important consumer: the } \\
\text { patient. This may yield substantial } \\
\text { benefits in the form of improved quality } \\
\text { and patient safety, reduced costs, } \\
\text { higher-value care, improved patient } \\
\text { outcomes, and greater patient and } \\
\text { provider satisfaction. }\end{array}$ \\
\hline
\end{tabular}


Table 3

Theme headings from narrative synthesis across three layers

\section{Factor Theme Headings}

Macro: Policy-level factors

Macro: Legal and ethical factors
All specialties

- 'Federal payment restrictions for telemedicine.'

- 'Inconsistency in coverage \& reimbursement.' across states and payers.'

- 'Interstate licensure and credentialing issues.'

- 'Data privacy \& security concerns.'

• 'Cyber-malpractice liability issues.'

Macro: Other structural factors

All specialties

- 'Growing healthcare costs.'

- 'Anticipated healthcare workforce shortages.'

- 'Changing population demographics.'

- Growing patient preference for telehealth.'

- 'Technological advancements.'

- 'Increasing patient acceptance of wearable technology.'

- 'Changing demands of profession (e.g., need for subspecialty expertise).'

Meso: Specialty-level historical rationale for telehealth use
Lower-using specialties

- 'Improving access to care.'

Higher-using specialties

- 'Improving quality of care' (e.g., patient outcomes/experience).

- 'Creating a business case for telehealth' (e.g., reducing costs and/or increasing revenues).

- 'Promoting population health' (e.g., creating disease registries for chronic care management).

Lower-using specialties

- 'Limited support for telehealth use in the specialty from hospitals/health systems.'

Higher-using specialties

- 'Extensive support for telehealth use in the specialty from hospitals/health systems' (e.g., spurred by one or more aims of the Triple Aim framework). 


\section{Factor}

Meso: Specialty-level professional society factors

Meso: Specialty-level treatment factors

\section{Theme Headings}

Lower-using specialties

- 'Limited or reactive support for telehealth use in from specialty-society'

Higher-using specialties

- 'Extensive or proactive support for telehealth use from specialty-society.'

- Specialty-society proactively promotes telehealth use in specialty, by influencing macro factors (payer reimbursement) and micro factors (provider practices and culture).'

Lower-using specialties

- 'Traditional encounter-based primary or specialty care.'

Higher-using specialties

- 'Holistic or integrated patient-centered care' (e.g., primary or specialty PCMH model).

Meso: Specialty-level technological factors

Lower-using specialties

- 'Interactive real-time video/audio modality.'

Higher-using specialties

- 'Interactive real-time video/audio modality.'

- 'Store-and-forward modality.'

• 'Remote Patient Monitoring (RPM) modality.'

Meso: Specialty-level research factors
Lower-using specialties

- 'Relatively lower penetration of telehealth-related outcomes research within the specialty,'

- 'Relatively lower translation of research to practice.'

Higher-using specialties

- 'Relatively higher penetration of telehealth-related outcomes research within the specialty.' 


\begin{tabular}{|c|c|}
\hline Factor & Theme Headings \\
\hline \multirow{8}{*}{$\begin{array}{l}\text { Meso: Specialty-level } \\
\text { cultural factors }\end{array}$} & Lower-using specialties \\
\hline & • 'Reimbursement-driven provider culture.' \\
\hline & • 'Resistance due to lack of reimbursement.' \\
\hline & • 'Orientation to 'Gatekeeper Role.' \\
\hline & - 'Resistance due to related to lack of telehealth training.' \\
\hline & • 'Fear of changing doctor-patient relationship.' \\
\hline & Higher-using specialties \\
\hline & • 'Entrepreneurial or pioneering (risk-driven) provider culture.' \\
\hline \multirow{4}{*}{$\begin{array}{l}\text { Micro: Individual } \\
\text { provider-level factors }\end{array}$} & Lower-using specialties \\
\hline & • 'Provider-centric telehealth practices.' \\
\hline & Higher-using specialties \\
\hline & • 'Patient-centric telehealth practices.' \\
\hline \multirow{4}{*}{$\begin{array}{l}\text { Micro: Individual } \\
\text { patient-level factors }\end{array}$} & Lower-using specialties \\
\hline & • 'Low patient preference for/engagement in telehealth use.' \\
\hline & Higher-using specialties \\
\hline & • 'High patient preference for/engagement in telehealth use.' \\
\hline
\end{tabular}

\section{MACRO: Policy-Level Factors}

Coverage and reimbursement for telemedicine are not federally regulated in the US. Moreover, there is considerable variability in rules across states and payers. Although the COVID-19 public health emergency has increased telemedicine coverage, nationwide standardization of coverage \& reimbursement policies are still lacking. $[16,89]$ Today, there are three broad categories of telemedicine technologies: 1) real-time interactive video (and audio) services; store-and-forward telemedicine involving the transmittal of data (such as medical images) to a physician or medical specialist for assessment; and 3) Remote patient monitoring (RPM), enabling medical professionals to monitor a patient remotely using various technological devices. $[16,36]$

For a large part of the pre-COVID era, Medicare paid for a relatively narrow list of telemedicine services. Additionally, patients were required to travel to an originating site to receive telemedicine services and these sites were generally limited to qualified centers in areas defined as rural Health Professional Shortage Areas (HPSAs). Also, telemedicine services covered by Medicare were required to have both interactive audio and video with real-time communication, with restricted payment options for store-and- 
forward and RPM telemedicine modalities. [16, 36, 37] Among other payers, there is considerable variation in coverage and payment for telemedicine across states and private insurers. [89]

There are some variations to be noted in Radiology and Psychiatry. Teleradiology services have been more consistently reimbursed by Medicare since early mid-1990s, due to the need for overnight (afterhours) reading services. However, it is important to note that to a large extent, teleradiology does not differ from traditional radiology because radiologists rarely interact with patients in person. Despite these advantages, teleradiology continues to be limited by contractual, billing, licensing, and credentialing issues. [82] Similar to teleradiology, telepsychiatry (which differs from other medicine specialties by not requiring a physical exam), was one of the earlier telemedicine specialties to be reimbursed by Medicare. However, Medicare has placed constraints on how telepsychiatry services can be used, and several states did not reimburse telepsychiatry visits at the level of an in-person visit. [72] In summary, in the pre-COVID era, policy-level constraints related to telehealth reimbursement were applicable across all six specialties.

\section{MACRO: Legal and Ethical Factors}

In the US, telehealth continues to be hindered by policies that vary substantially across states and payers, especially those related to rules for interstate licensure and provider credentialing. [39, 89, 90] Historically, physician licensing mandates have required physicians to carry a medical license in the state of patient residence. For example, in telepsychiatry, each state has its own licensing boards that establish practice jurisdictions for providers licensed in the state, and some have specific regulations. [72, 90] Similarly, the legal environment for teleradiology in the US is a limiting factor. For comprehensive services with final reading, radiologists need to be licensed in the remote institution's state, credentialed in the institution and insured for medico-legal liability. [82, 90] In addition, legal factors such as HIPAA concerns, ethical concerns related to data privacy \& security, and malpractice and cyber-liability, have historically had a big role to play constraining telehealth use across all specialties.

\section{MACRO: Other Structural Factors}

Similar to policy-level factors and legal \& ethical factors that have historically influenced telehealth use, a variety of societal-level structural factors have also influenced the course of telehealth use across medical specialties and are likely to continue to play a role in the post-pandemic era. These include growing healthcare costs, anticipated healthcare workforce shortages, changing population demographics, changing patient preferences for telehealth, technological advancements, and increasing patient acceptance of wearable technology, among others.

For example, in Gastroenterology the staggering growth in healthcare costs have given rise to new valuebased delivery models, e.g., Specialty Patient-Centered Medical Homes (Specialty-PCMHs), targeted towards the treatment of Inflammatory Bowel Disorders (IBDs), while a number of other conditions in Gastroenterology (e.g., acute diarrhea, non-infectious colitis) continue to receive traditional specialty care. $[44,50]$ In Allergy-immunology, concerns related to the sustainability of health care workforce including the projected shortage of 130,000 physicians by 2025 (with approximately only 3,000 active allergists nationwide) is gradually influencing the specialty to favor telehealth adoption. [37, 39] The field of Family 
Medicine faces increasing patient demands for telehealth, low rates of telehealth adoption in general primary practice, and growing pressures to provide proactive and holistic population-based health care, within a fragmented healthcare system. [56] The field experienced a convergence of all three pressures during COVID-19. [56, 60] Entering the pandemic, much of the needed informatics infrastructure for primary care was poorly developed-for telehealth, clinician communication, and home hospital care. At the onset of COVID-19, the Medical Group Management Association reported the pandemic's devastating impact on the provision of primary care across the nation. By April 2020,97\% of practices had experienced a negative financial impact; and on average, practices report a $55 \%$ decrease in revenue and $60 \%$ decrease in patient volume, since early 2020. [91]

In Cardiology, the use of the remote monitoring of cardiac patients (RPM) is growing substantially, as a result of both technological advancement and patient acceptance of wearable technology. [63, 70, 71] Many implantable cardiac devices now continuously collect and transmit data back to clinicians. In Psychiatry, the demand for mental health services will continue to be higher than the supply of providers in the near future; thus, there is an urgent need for expedient integration of technology into innovative models of mental healthcare. $[76,80,90]$ In Radiology, several structural factors have potential to impact the future of teleradiology, including growing need for subspecialty expertise in the field (e.g., pediatric teleradiology) as well as contractual, billing, and workforce challenges. [82] Historically, "billing wars" with other professions for image reading services has spurred large segment of the profession to outsource their expertise to teleradiology companies, resulting in commoditization of the profession, conflict and debate within the specialty, and unique workforce challenges to contend with in teleradiology. [92] In summary, a variety of structural factors have historically influenced and are expected to continue to influence the course of telehealth use across specialties, in the post-pandemic era.

\section{MESO: Specialty-level historical orientation to telehealth}

Among "lower-using" specialties, telehealth adoption in Allergy-Immunology was low in the pre-pandemic era, despite substantial growth in other internal medicine subspecialties (e.g., Cardiology). The historical rationale for telemedicine use in this specialty was to "improve access to care" for underserved populations. [36, 37, 39] In other words, in this specialty, telehealth was not viewed as a tool to 1) improve patient experience (e.g., by empowering patients to take control of their asthma); or 2) generate cost savings (e.g., by reducing clinic no-show rates or asthma-related hospitalizations) or 3 ) to promote population health (by improving asthma self-management effectiveness).

In Family Medicine, studies have shown substantial variation in telehealth use depending on, practice ownership, type of care provided, use of electronic health record (EHR), and practice location. [54-56] For example, a 2017 article revealed that family physicians (FPs) in private practices, providing general primary care to patients, were significantly less likely to use telehealth compared to counterparts in hospital/health system owned practices, and significantly more likely to use telehealth if they were already using an EHR and integrated with a health system. [54] Since a large number of FPs continue to provide general primary care, it helps to explain the overall lower use of telehealth in family medicine. FPs 
who used telehealth were also more likely to be located in a rural setting, conveying a historical rationale to using telehealth to "improve access to care" (similar to Allergy-Immunology). [54]

In Gastroenterology, there are differences in telehealth use for the treatment of IBD vs. non-IBD conditions. While the historical rationale of "improving access to care" has prevailed for traditional specialty care of non-IBD conditions (e.g., non-infectious colitis), an alternate rationale of "improving patient experience and reducing costs" through value-based delivery models (like Specialty-PCMHs), has taken root for the treatment of IBDs. $[45,49,50]$ The PCMH model in turn, entails systematic use of telehealth, including interactive video and RPM modalities in the treatment of IBD. [44, 45] Since a large number of gastroenterologists continue to provide traditional specialty care for non-IBD conditions, it helps to explain the overall lower use of telehealth in this specialty. [49]

Among "higher-using" specialties, Cardiology is regarded as a clinical specialty that has most benefitted from the use of telemedicine. There is a long history of pioneers in telecardiology, the first experiences of telecardiology were carried out in 1903 sending electrocardiograph from a hospital to a laboratory. [62, 93, 94] Historically, providers and hospital organizations have undertaken telecardiology to improve health outcomes, improve patient experience, reduce costs (e.g., through decreased re-hospitalizations for heart failure), and increase revenues from participation in federal pay-for-quality programs (introduced in the early 2000s in the US). [95] Technological improvements have also boosted interest in the use of telemedicine in cardiology. For example, cardiologists have long sent devices such as Holter monitors home with patients to gather data on heart rhythms over months. Emergency services also routinely use telecardiology consultations to guide prehospital care decisions. Remote monitoring of cardiac patients has also grown substantially due to increasing patient acceptance of wearable technology. Clinical trials have shown these devices to benefit patients by helping detect arrhythmias more quickly, thereby reducing hospitalizations for arrhythmias and strokes, and eliminating the need for some clinic visits. [17, $62,94]$

Psychiatry is credited with playing a pioneering role in the field of telemedicine. Telepsychiatry has its origins in the 1950s, and The University of Nebraska's Nebraska Psychiatric Institute hosted the first video-based psychiatric consults in 1959. [73,94] Although it began to be used as a tool for providing mental healthcare in remote areas, early pioneers in the field began using it for improving the patient experience. Presently, it is considered a mainstream practice, integral to maximizing patient-centered care outcomes and patient and provider satisfaction. Telepsychiatry has been proactively championed by psychiatric specialty society, American Psychiatric Association (APA) from an early adoption stage to mainstream practice in the field. $[73,74] \mathrm{A}$ significant amount of research has demonstrated the advantages of telepsychiatry beyond increasing access to care. Use of telepsychiatry leads to high patient and provider satisfaction ratings and achieves health outcomes equivalent to in person care. Younger generations-children and adolescents-particularly prefer telepsychiatry over in-person face-toface encounters, due to their familiarity with video apps. Telepsychiatry is versatile and is already used in a variety of settings. $[78,90]$ 
In Radiology, teleradiology is by far the most heavily used telemedicine service. It accounts for more than half of all telemedicine cases performed in the United States each year. The historical rationale for teleradiology was to meet the need for after-hours coverage for hospital-based emergent radiologic studies. [82, 92] Some have suggested that patient satisfaction may be an incentive in some practices as a means for expediting service. As such, the rationale for telehealth use emanated from the combined need to both improve quality and preserve revenues (business case) for the profession. The latter was owing to the fact that Medicare changed its payment system in mid-1990s which served to benefit other specialty groups like emergency physicians and orthopedists, who had an advantage over radiologists in completing 'first readings' of images. Radiologists responded to this challenge by offering 24-hour coverage for emergent radiology. [92] Early acceptance of teleradiology by the profession and the adoption of guidelines have resulted in professional conformity to assure quality and safety.

\section{MESO: Specialty-level hospital-organizational factors}

Historically, due to gaps in reimbursement, telehealth initiatives had to be undertaken at hospital or provider levels. Correspondingly, such initiatives were often viewed as 'organizational learning experiments;' required an entrepreneurial (risk-taking) mindset on the part of individual providers, often with support from hospital-organizational and specialty-society leadership. [5] For such telehealth initiatives, the Return on Investment (ROI) on telehealth was considered a long-term matter. It would likely be achieved through reduced numbers of patient visits at physical sites (optimizing utilization) and decreased number of high-cost events like hospitalizations. As such, in the pre-COVID era, owing to limited support from payers, many prevailing telehealth activities were financed by providers. $[5,8]$

Among "lower-using" specialties, historically, there has been limited support from hospitals and health systems for telehealth use in Allergy-Immunology. [39] On the other hand, hospital organizations have leveraged other specialties to cash in on the 'business case' for telehealth, e.g., attracting younger patients through telepsychiatry, and using telecardiology to improve outcomes (e.g., reduce readmissions for heart failure), reduce costs, and earn pay-for-quality incentives. $[62,68,93]$ In Family Medicine, studies show that FPs who were integrated with health systems and used an EHR, were more likely to use telemedicine. [54] Likewise, in Gastroenterology, physicians affiliated with large integrated health systems have undertaken initiatives to establish Specialty-PCMHs for IBD care. [46]

Among "higher-using" specialties, in Cardiology, federal pay-for-quality programs created a dual incentive (quality improvement and cost savings) for hospitals and health systems to use telecardiogy. [62, 95] As a telemedicine specialty, Psychiatry has benefitted from extensive support from hospitals organizations. Health systems have historically adopted telepsychiatry to create a competitive advantage in attracting patients. [75-78] A shortage of psychiatrists nationwide has contributed to the enthusiasm for telepsychiatry. The largest health system in the US, the Veterans Health Administration, has embraced telepsychiatry. $[78,90]$ It would be relevant to note that Telepsychiatry is still largely supported by internal or grant funding-such as within the US Department of Veterans Affairs (VA). Telepsychiatry has also expanded considerably into the correctional setting. [79] Similarly, in Radiology, teleradiology has received tremendous support from hospitals and health systems. Historically, the main driver for 
teleradiology was the need for after-hours coverage for hospital-based emergent radiologic studies, which remains true today. $[82,83]$

\section{MESO: Specialty-level professional society factors}

Among "lower-using" specialties, the involvement of the American Academy of Allergy, Asthma \& Immunology (AAAAI) in providing guidance on telehealth use in Allergy-Immunology has been fairly recent, with more heightened involvement during COVID-19. As recently as 2017, the AAAAI issued a position statement acknowledging that allergy providers have historically found it daunting to get started due to inconsistency in reimbursement and multiple steps involved in launching a telemedicine program, including integration with EHR, concerns related to data privacy, security, and fear of endangering the doctor-patient relationship. [39] The AAAAl has also acknowledged 1) the need for clinician education on telemedicine's impact on the workflow, and 2) need for clinician training related to equipment, protocols, as well as telehealth-related patient education. The society has also articulated the need for hospitalorganizational support for patient education, indicating that it has historically not taken the lead in promoting telehealth use among patients within the specialty. [36, 39]

In Family Medicine, the American Academy of Family Physicians (AAFP) has historically played an active role in advocating for technology use in primary care. However, the emphasis was largely on influencing policies related to meaningful use of EHRs, including interoperability of EHR and need for integration of data sources (e.g., social determinants of health into primary care, to enable holistic population healthcare) to fulfill the premise of PCMHs. [58 59] Relatively less attention was paid by AAFP to telehealth per se in primary care, in the pre-pandemic era. Nevertheless, following the devastating impact of COVID-19 on primary care, the field has acknowledged that many barriers were present to an effective pandemic response in primary care, including an inadequate informatics infrastructure for telehealth, clinician communication, and home hospital care. In the midst of the pandemic, field leaders have issued recommendations for redesigning primary care by adopting proactive population care through the combined use of disease registries and telehealth. [56]

In Gastroenterology, although the American College of Gastroenterology (ACG) has helped to support adoption of telehealth adoption for IBD care within a value-based (specialty-PCMH) delivery model, it has remained more reactive in supporting telehealth adoption in traditional specialty care, with guidelines limited to evidence-based care practices for several conditions (e.g., acute diarrhea) without proactive promotion of telehealth use in the treatment of those conditions. $[49,50,96]$ Not surprisingly, most data on telehealth use in this specialty is available in the context of care for IBDs, where it has demonstrated decreased costs, improved quality of life, and decreased relapse rates. [47]

Among "higher-using" specialties, in Cardiology, the American College of Cardiology (ACC) and American Heart Association (AHA) have played an active role in promoting telehealth by: 1) advocating for better reimbursement, 2) supporting providers in overcoming reimbursement issues and 3 ) educating providers on how to design and implement a sustainable telehealth infrastructure. $[65,66,69,71]$ Likewise, in Psychiatry, the American Psychiatric Association (APA) has played an active role in developing and 
promulgating guidelines and best practices in telepsychiatry from early stages of adoption. The APA has also collaborated with the American Telemedicine Association (ATA) to develop best practices for videoconferencing-based telemental health. [74] Importantly, the APA has played an active role in both advocating for effective reimbursement for telepsychiatry and providing in-depth guidance to providers on 1) how to get started with telepsychiatry, 2) how to defray costs associated with developing infrastructure for telehealth, and 3) how to effectively design \& implement telehealth services for sustainability. [73, 74, 97] Similarly, in Radiology, the American College of Radiology (ACR) has played an active role in the promotion and institutionalization of teleradiology. [82, 83, 85]

\section{MESO: Specialty-level treatment factors}

Among "lower-using" specialties, telehealth could be used to provide a variety of treatments in AllergyImmunology, including telehealth for asthma and antibiotic allergy \& stewardship, home-based videos for triage, to isolate and protect providers, as well as telehealth for chronic disease management. [36, 37, 42] As such, the field is uniquely positioned to benefit from telehealth. Historically however, these unique opportunities for remote asthma management through telemedicine have been under-leveraged, and the field has been characterized by traditional in-clinic encounter-based care for asthma. In Family Medicine, a large number of providers are still engaged in provision of general primary care in small-to-mid-size private practices, as opposed to integrated PCMH arrangements, and the latter in turn, are more conducive to using telehealth for chronic disease management and population health. [44] In Gastroenterology, telehealth is being increasing used in value-based (specialty PCMH) delivery models to treat and coordinate care for individuals with IBD. [45] These lifelong, chronic inflammatory conditions affect the gastrointestinal tracts of 1.6 million Americans, with a rising incidence rate. IBD is generally diagnosed in young adulthood, and estimated to account for between \$14-31 billion in healthcare costs. IBD patients require integrated medical and surgical management and have higher rates of behavior comorbidities. Thus, IBD may be uniquely situated as a chronic disease with a high economic burden and more focused medical needs to benefit from a PCMH model. [47]

Among "higher-using" specialties, in Cardiology, telehealth can be used for real-time, remote diagnosis and treatment of heart disease. It can be used to evaluate heart disease, congestive heart failure, cardiac arrest and arrhythmias. Telecardiology's applications are extensive and can occur before, during and after hospitalization, giving it the power to increase access to cardiovascular care not only in rural regions but also within cities' underserved areas. $[62,63,68]$ Importantly, telecardiology can be used for remote patient monitoring. In Psychiatry, although telepsychiatry has been used clinically for most diagnoses, research studies have emphasized certain diagnoses more than others. [78] Studies suggest that posttraumatic stress disorder (PTSD), depression, and anxiety were more likely to be addressed using telepsychiatry than alcohol use disorders, substance use, and psychotic disorders. [72] Telepsychiatry has been found to have the potential to bridge ethnic disparities in mental health, providing care for underserved ethnic or demographic groups, including American Indian, Hispanic, and Asian populations. [77] Telepsychiatry has also been found to be beneficial among child and adolescent populations. [81] In Radiology, medical doctors are trained in diagnosing and treating injuries and diseases using the images 
acquired by various modalities and they also perform a variety of minimally invasive interventions such as biopsies and embolization to block blood flow. [82]

\section{MESO: Specialty-level technological factors}

Among "lower-using" specialties, in Allergy-Immunology, providers have indicated a preference for interactive video over other modalities owing to availability of reimbursement. Although telemedicine has been historically under-leveraged in this specialty, studies show that all types of telemedicine visits are possible in Allergy-Immunology, including remote and synchronous. The range of treatment lends itself to all modalities, including triage or second opinion care, proxy care, virtual visits, store-and-forward and remote monitoring. There is also great potential to apply emerging technologies like e-diaries, wearable devices, and digital inhalers in this specialty. [36, 38] Telehealth for asthma management also has considerable potential for application in both school and correctional settings. [38, 40] In Family Medicine, a majority of telehealth users have indicated preference for real-time interactive video, compared to the RPM modality, which is more conducive for chronic disease management. [54] In Gastroenterology, treatment of IBD through Specialty-PCMHs involves leveraging all three telemedicine modalities of interactive video, store-and-forward, and RPM. [47, 52]

Among "higher-using" specialties, in Cardiology, all three forms of telemedicine modalities, interactive visits, store-and-forward for tele consultations and connecting hospitals, and RPM for disease management are applicable in telecardiology. $[68,69]$ In Psychiatry, telemedicine is expanding beyond its original roots of interactive video and synchronous communication and into asynchronous communication. [76] In Radiology, teleradiology is primarily based on the store-and-forward, i.e., electronic capture, transmission, and retrieval of images for remote viewing and interpretation. [82, 87]

\section{MESO: Specialty-level research factors}

A PUBMED search of articles reporting results of telehealth-related clinical trials by specialty, over 10 years preceding the COVID-19 pandemic (2010-2019), revealed a total of 16 articles in AllergyImmunology, 48 in Gastroenterology, 263 in Family Medicine, 219 in Cardiology, 622 in Psychiatry, and 203 in Radiology. Overall, these results indicate lower penetration of telehealth-related outcomes research in "lower-using" specialties compared to "higher-using" specialties, with the exception of Family Medicine, in which preponderance (over 75\%) of articles pertained to $\mathrm{PCMH}$ in primary care. The latter indicates considerable research on medical homes in primary care, with a relatively lower rate of translation of research to practice, since $\mathrm{PCMH}$ is still a nascent concept in primary care practice.

Nevertheless, even among "lower-using" specialties, studies serve to demonstrate considerable benefits of telehealth use. For example, these benefits have been demonstrated across all domains of AllergyImmunology, including school-based and prison-based telehealth for asthma management. [3639]Among "higher-using" specialties, a large evidence base has documented improved outcomes in telecardiology, with growing research in the area of RPM. Similarly, telepsychiatry has been evaluated extensively, in accordance with the Triple Aim Framework which addresses patient satisfaction, care quality, and cost effectiveness. Evidence indicates that patients are satisfied, telepsychiatry is 
comparable to in-person delivery of mental health interventions and can be a cost-effective approach to increasing access to mental health care. $[75,78]$ Likewise, the evidence regarding the feasibility of teleradiology and related applications has been well established for over two decades. [82]

\section{MESO: Specialty-level cultural factors}

Among "lower-using" specialties, telehealth has historically not been considered part of mainstream practice in Allergy-Immunology. Providers' resistance to change in the face of lack of reimbursement is a recognized barrier to telehealth use in the field. However, recent literature has acknowledged that a historical orientation to a 'gatekeeper' role among allergy providers (i.e., a desire to maintain control over treatment options and prevent changing the dynamics of the physician-patient relationship), may have had a significant role to play in slowing telehealth use. $[37,98]$ In Family Medicine also, the literature indicates a traditional reimbursement-driven provider culture related to telehealth use. Lack of reimbursement from insurers and lack of training on how to use telehealth were the most common barriers to telehealth use. [54] The field acknowledges that if telehealth services are to have a major impact in primary care, more family physicians will need to become experienced in using these services [56]. Similarly, in Gastroenterology, the literature discusses the general concern among providers that telehealth has potential to change the dynamics of the physician-patient relationship. $[49,53]$

Among "higher-using" specialties, the provider culture associated with telehealth in Cardiology can be best described as pioneering and patient-centric. Increasingly, cardiologists across the country are leveraging technology to provide virtual visits, consultations, or monitoring using a growing array of implantable or wearable devices. $[63,70,93]$ Likewise, in Psychiatry a historical orientation towards maximizing patient-centered outcomes drove early adoption of telehealth, indicating pioneering and patient-centric provider culture. [73, 90,97] As discussed earlier, Radiology was one of the earliest adopters of telemedicine, indicating an entrepreneurial and pioneering provider culture. $[87,88]$

\section{MICRO: Individual provider-level factors}

Among "lower-using" specialties, individual provider practices associated with telehealth in AllergyImmunology could be best described as "provider-centric," oriented towards the 'gatekeeper' role, rather than "patient-centric." The pandemic literature acknowledges that historically, allergists believed that skin tests and food challenges needed to be treated in person and that asthma could not be treated without spirometry. In a new COVID-19 era, allergists are finding out that they can use telemedicine for just about every patient and that treatment can be based on symptoms. [37, 98] The literature also acknowledges that lack of initiative on the part of allergy providers to educate patients about telehealth options, may have limited growth in patient demand for telehealth in the field. [39] In Family Medicine, while provider practices among general primary care physicians could be characterized as "provider-centric," physicians engaged in PCMH arrangements can be described as more "patient-centric" in their practice and orientation. [56, 59] In Gastroenterology (similar to Family Medicine), while physicians in traditional specialty care have been more "provider-centric" in practice, providers of IBD care have embraced more "patient-centric" practices in value-based specialty PCMH models of care. [44] 
Among "higher-using" specialties, in Cardiology, thousands of providers have embraced patient-centric care through virtual visits, teleconsultations, and RPM in the inpatient and outpatient settings. [62] In Psychiatry, patients and clinicians are largely satisfied with telehealth, and the field could not have gone from esoteric curiosity to mainstream practice without the pioneering commitment of many clinicians who began using telehealth to improve the patient experience. [78] Likewise, in Radiology, individual providers displayed patient-centric practices in offering 24-hour radiology services. [82, 88]

\section{MICRO: Individual patient-level factors}

Historically, in many "higher-using" specialties, a large part of the move to adopt telehealth was driven by patient preference. [98-100] A 2019 survey demonstrated that patients are willing to use telehealth, but barriers exist: 1) at a time of need people revert to what they are used to doing and the way in which they previously interacted with the system;2) patients would prefer that they see their own provider through telehealth; 3) patients may be unaware that they have telehealth as an option. [101] As such, the literature acknowledges the need for initiative on the part of providers to overcome these barriers by 1) educating people that telehealth is an effective and safe alternative, 2) expanding network reimbursement coverage to see patients through telehealth, 3) making people aware that a telehealth benefit exists, with instructions for access, 4) helping people understand how telehealth works, and 5) continuing to reduce cost barriers to accessing telehealth. $[98,102]$

As discussed earlier, among all three "lower-using" specialties, provider level initiative towards patient awareness-building and education related to telehealth has been limited. On the other hand, among "higher-using" specialties, there have been proactive efforts on the part of providers (including hospital and specialty organizations) to partner with and engage patient in telehealth services. $[36,49,56]$ For example, in Cardiology, telemonitoring has been found to improve seniors' confidence in evaluating and addressing their symptoms in relation to heart failure. $[63,68]$ Likewise, in Psychiatry, a socioeconomically and clinically diverse patient population has reported that they are comfortable using this technology and appreciate the practical benefit of avoiding travel. [78] Similarly, telemedicine participants in Radiology have benefited from improved quality and efficiency, including improved type of treatment, image interpretation, and reduced postoperative complications. [82]

\section{Discussion}

The narrative synthesis by layer, helped to understand that there was limited variation across the six medical specialties, with respect to factors influencing telehealth use in the macro layer (including policylevel, legal/ethical and other structural factors). On the other hand, distinct themes emerged among "lower-using" and "higher-using" specialties, with respect to factors influencing telehealth use in meso and micro layers. For example, the review revealed that the historical rationale for telehealth use in "lowerusing" specialties (Allergy-Immunology, general primary care practice in Family Medicine, and traditional specialty care for Gastroenterology), was 'improving access to care,' indicating a limited view of the role of telehealth in healthcare delivery. [37, 49,54] By contrast, "higher-using" specialties had progressed beyond using telehealth to improve access, to using it to maximize patient-centered healthcare delivery, 
improve outcomes, reduce costs, enrich the patient experience, and promote population health. $[62,72$, 82]

Similarly, the reviewed revealed there was the limited support from hospitals and health systems for telehealth adoption in "lower-using" specialties (e.g., Allergy-Immunology), compared to more extensive support for "higher-using" specialties (e.g., Cardiology, Psychiatry). [39, 68, 78] The Triple Aim framework for healthcare delivery: i) better patient experience, ii) lower cost, and iii) improved population health can help to understand hospital organizations' motivation for telehealth use in a specialty.[82] We learned that hospitals were able to make a "business case" for telehealth adoption in Psychiatry (by marketing to younger patients) and Cardiology (by reducing readmissions for heart failure, lowering costs, and earning pay-for-quality incentives). $[62,66,75,93]$ The review also revealed that hospital support for telehealth use in those same specialties, was supplemented by proactive support from respective specialty societies to advocate for better reimbursement, provide guidelines for telehealth use, provide training on how to design and implement a successful telemedicine infrastructure, and develop resources for provider engagement of patients. $[65,75]$

Concurrently, each "higher-using" specialty is replete with examples of initiatives from individual providers, to improve patient experience, enable disease management, reduce costs, and promote population health, which reveals an entrepreneurial and patient-centric culture as opposed to a reimbursement-oriented, provider-centric culture. $[62,72,88]$ In other words, in the "higher-using" specialties all three levers of the Triple Aim framework appear to have been in motion, serving as motivators for telehealth use at the provider (micro) and organizational (meso) levels. By contrast, all three motivators appear to have been missing among the "lower-using" specialties. [39, 54]

To the best of our knowledge, this is the first attempt to review and synthesize the literature to examine factors influencing telehealth use across multiple medical specialties. The review is timely in that, there has been substantial emphasis on telehealth adoption during the COVID-19 pandemic, with great benefits to public health, however, several uncertainties remain in regard to the potential for widespread sustainability of telehealth in a post-pandemic era. $[19,20]$ As mentioned earlier, Ly et al $(2017)$ used the macro-meso-micro framework to examine individual and contextual factors explaining telehealth adoption in Senegal. However, their study focused on telehealth adoption in general, rather than across specialties, and their meso layer was restricted to technical and organizational factors. [34] By focusing on variation in telehealth use across specialties, this review was able to examine the influence of an expanded set of specialty-level factors on telehealth use in the meso layer, including specialty-society and hospital organizational factors. A key inference of Ly et al (2017) was that individual intention to use telehealth (in micro layer) was impacted by technical factors (in meso layer), which in turn is heavily influenced by policy factors like reimbursement (in macro layer). Our review revealed substantial potential for specialty and hospital organizations (in mesolayer) to positively impact telehealth adoption even in the face of reimbursement constraints, by influencing both macro factors (e.g., advocating for better reimbursement) and micro factors (e.g., influencing provider practice to be more tech-savvy and patient- 
centric). By examining an expanded set of specialty factors therefore, this review creates the opportunity for "lower-using" specialties to learn from "higher-using" specialties.

\section{Strategies for reducing variation in telehealth use across medical specialties}

The literature has discussed how the likelihood of success of a telemedicine program is increased when it offers: 1) Gap service coverage, e.g., teleradiology; 2) Urgent service coverage, e.g., telestroke, teleburn, teletrauma, etc. 3) Mandated services, e.g., correctional telemedicine; 4) Video-enabled multi-site group chart rounds. The Extension for Community Healthcare Outcomes $(\mathrm{ECHO} \otimes)$ program developed group chart clinical rounds that are managed over telemedicine networks. [90] The underlying concept is that specialists in the management of specific chronic diseases can maximize their effectiveness by mentoring a group of primary care physicians on how to manage these diseases.

Among "higher-using" specialties examined in this review, teleradiology already provides a gap service coverage, while telepsychiatry provides mandated service coverage for correctional health. Similarly, telecardiology has been leveraged extensively for both urgent service coverage, e.g., for balloon angioplasty or percutaneous coronary intervention, and in $\mathrm{ECHO}{ }^{\circledR}$ models seeking to connect cardiologists in with primary care physicians in rural areas. $[69,79]$

"Lower-using" specialties could learn from higher-using counterparts. For example Allergy-Immunology could explore providing mandated service coverage, e.g., correctional health. Also, given the anticipated shortage of allergists nationwide, the field could greatly benefit from systematic collaborations with Project $\mathrm{ECHO}{ }^{\circledR}$ to integrate medical education with clinical practice and connect specialists with primary care physicians in rural areas. Likewise, in Gastroenterology, providers practicing in non-IBD traditional specialty care not affiliated with PCMHs could explore opportunities for participation in Project ECHO ${ }^{\circledR}$ style group rounds for non-IBD gastrointestinal disorders. Family Medicine could also greatly benefit from exploring provision of a gap service such as tele-transitions of care, an approach to reduce 30-day readmission by incorporating telehealth technologies into patient care, and targeting patients most at risk for readmission. [57]

\section{Implications for widespread sustainability in telehealth use in a post-pandemic era}

This review indicates that lack of telehealth training, lack of reimbursement, orientation to gatekeeper role and resistance to changing the doctor-patient relationship, could all hinder telehealth adoption at the provider (micro) level. Specialty and hospital organizations could play a proactive and organized role in addressing each of these barriers, by advocating for consistent payment policies from payers; providing guidelines for telehealth use; training providers on how to design \& implement a successful telemedicine infrastructure; advocating for telehealth training in the medical residency curriculum; and engaging patients in telehealth through outreach and education. Such organized efforts could go a long way in 
influencing provider practices within the specialty to be more: tech-savvy (to design effective telehealth workflows); patient-centered (to manage patient behavior); efficiency-driven (to reduce clinic no-shows, increase patient convenience); business-oriented (to reduce costs and increase revenues); safety-oriented (to keep patients safe from community exposure); and population health-focused (to improve selfmanagement and reduce hospitalizations).

No doubt, specialty and hospital organizations would be reliant on federal, state, and private payers to consistently reimburse for telehealth services. However, our findings suggest that specialty and hospital organizations could play a proactive role in promoting telehealth use in the specialty, by influencing both macro factors (e.g., advocating for better reimbursement); and micro factors (e.g., influencing both provider practices and patient preferences for telehealth). For example, to overcome the "getting started" barrier, specialty societies like the AAAAI and AAFP could play a significant role in preparing providers for effective design and implementation of telehealth services in the clinic setting. Effective telehealth design requires application of holistic design thinking or systems thinking principles in the context of care delivery. At the same time, effective implementation requires active stakeholder engagement, end-user buy-in, comprehensive training and education, and quality measurement for continuous improvement. Specialty societies in "lower-using" specialties could play an active role in developing strategies and best practices for effective telehealth design and implementation for providers. At the same time, they could play a significant role in training providers (train the trainer) to be proactive and innovative in engaging patient participation in telehealth services.

Sustainability of telehealth requires funding support beyond grant funding as in the case of VA's ongoing funding support for telepsychiatry services. Providers in "lower-using" specialties could be proactive in making a case for ongoing funding support for telehealth services from hospitals and payers, by undertaking initiatives to achieve one or more aims in the Triple Aim framework. For example, providers in Allergy-Immunology could undertake active efforts to use RPM to monitor patients' asthma management to prevent asthma-related hospitalizations, reduce costs, and promote population health. Such efforts could go a long way in attracting hospital and payer support for telehealth in Allergy-Immunology, in an era of value-based reimbursement.

\section{Limitations, strengths, and future research avenues}

There are some limitations and strengths to be noted, along with future research avenues. First, there are no empirical studies that have sought to assess direct relationships between all specialty-level factors identified in this review, and telehealth use in a specialty. Most available studies on telehealth use have been cross-sectional and have examined organizational and individual-level influences on telehealth use. $[10,34]$ Concurrently, studies that have sought to examine telehealth use across specialties, have examined association between structural and market characteristics and telehealth use, while others have examined hospital/health system-level telehealth adoption, by specialty. $[5,7,8]$ To the best of our knowledge, a number of meso specialty-level factors examined in this review, including the influence of historical rationale for telehealth use and specialty-society factors on telehealth use, have not been examined in a systematic way, alongside macro policy-level and micro provider-level factors. This review 
provides a foundation for more comprehensive (holistic) future research on telehealth adoption that takes into account a variety of contextual factors (at macro and meso levels) and individual factors (at the micro level). Longitudinal studies are recommended to understand the full impact of specialty-level factors on telehealth use in a specialty.

In the absence of systematic empirical evidence, the use of narrative synthesis instead of a quantitative, meta-analytic review is not only justified, but highly appropriate, as it provided the opportunity to use words and text to understand the specialty-level factors historically influencing telehealth use across medical specialties, based on review and synthesis of a range of peer-reviewed literature in each specialty. It would be relevant to note however, that since the findings were synthesized across six specialties represented in this review, the potential for within-specialty variation needs to be acknowledged. For example, although Psychiatry is a "higher-using" specialty, it has not been without its challenges of institutional barriers, including provider resistance to change. Similarly, although it has received consistent funding support from the VA, several telepsychiatry projects have not been sustained due to lack of funding, long-term planning and technical barriers. [97, 103]

Despite these limitations, this is an original attempt to examine contextual, individual, and interaction factors influencing telehealth use at the specialty level, and how these factors might influence attempts to increase widespread use and sustainability across specialties, in a post-pandemic era. Although the study is original in scope and focus, findings are sufficiently similar to other study results where original evidence available, like for example, on the role of hospital organizational factors in telehealth adoption, including varying support for specialties. $[7,8,104]$ Correspondingly, the results of this review represent potentially transferable knowledge for future research avenues. For immediate purposes, as discussed earlier, the results provide insights into strategies for reducing variation in and promoting sustainability of telehealth use across medical specialties, in a post-pandemic era.

\section{Conclusion}

This review is original in identifying a comprehensive set of contextual and individual factors, and their interactions, in influencing telehealth use across medical specialties. It thereby addresses a gap in the literature and provides a foundation for future research. Importantly, the results provide insight into strategies for reducing variation in telehealth use across medical specialties and increasing widespread sustainability in a post-pandemic era. A key insight gained, is that specialty societies and hospital organizations at the meso level, could play crucial role in creating the conditions needed for success and sustainability of telehealth use in a medical specialty, by concurrently addressing both the tangible barriers (reimbursement, training, workflow, design, implementation etc.) and the intangible barriers (provider cultures and mindsets) influencing telehealth use, at macro, meso, and micro levels.

\section{Abbreviations}

- US: United States 
- HRSA: Health Resources Services Administration

- PRISMA: Preferred Reporting Items for Systematic Reviews and Meta-Analyses

- HPSA: Health Professional Shortage Area

- RPM: Remote Patient Monitoring

- EHR: Electronic Health Record

- FP: Family Physician

- PCMH: Patient-Centered Medical Home

- AAAAl: American Academy of Allergy, Asthma \& Immunology

- ACG: American College of Gastroenterology

- AAFP: American Academy of Family Physicians

- ACC: American College of Cardiology

- AHA: American Heart Association

- APA: American Psychiatric Association

- ATA: American Telemedicine Association

- ACR: American College of Radiology

- ROI: Return on Investment

- IBD: Inflammatory Bowel Disorder

- MGMA: Medical Group Management Association

- ECHO: Extension for Community Healthcare Outcomes

- VA: Veterans Affairs

\section{Declarations}

- Ethics approval and consent to participate: Not applicable.

- Consent for publication: Not applicable.

- Availability of data and materials: The data generated and/or analyzed during the current study, has been made available as Supplementary Material (Appendix 3).

- Competing interests: The authors declare that they have no competing interests.

- Funding: This review received no external funding.

- Authors' contributions: PR conceptualized the review effort. PR, SW, and KH developed and implemented the review protocol. PR prepared the original draft of the manuscript. All authors (PR, SW, and $\mathrm{KH}$ ) contributed with critical feedback to drafts and read and approved the final manuscript.

- Acknowledgments: Not Applicable.

\section{References}


1. Health Resources and Services Administration. Telehealth; https://www.hrsa.gov/library/telehealth; Retrieved September 5, 2020.

2. National Coordinator for Health Information Technology. Telemedicine and Telehealth https://www.healthit.gov/topic/health-it-health-care-settings/telemedicine-and-telehealth; Retrieved September 5, 2020.

3. Telehealth Alliance of Oregon. Telemedicine or Telehealth Definitions. https://www.ortelehealth.org/content/telemedicine-or-telehealth-definitions; Retrieved September 2, 2020.

4. National Telehealth Policy Resources Center. About Telehealth; https://www.cchpca.org/about/about-telehealth; Retrieved September 10, 2020.

5. Schwamm LH. Telehealth: seven strategies to successfully implement disruptive technology and transform health care. Health Aff (Millwood). 2014 Feb;33(2):200-6. doi: 10.1377/hlthaff.2013.1021. PMID: 24493761.

6. Taylor PR. An approach to designing viable and sustainable telehealth services. Stud Health Technol Inform. 2013;188:108-13. PMID: 23823297.

7. Kane CK, Gillis K. The Use Of Telemedicine By Physicians: Still The Exception Rather Than The Rule. Health Aff (Millwood). 2018 Dec;37(12):1923-1930. doi: 10.1377/hlthaff.2018.05077. PMID: 30633670.

8. Lin CC, Dievler A, Robbins C, Sripipatana A, Quinn M, Nair S. Telehealth In Health Centers: Key Adoption Factors, Barriers, And Opportunities. Health Aff (Millwood). 2018 Dec;37(12):1967-1974. doi: 10.1377/hlthaff.2018.05125. PMID: 30633683.

9. E-visit; 5 Healthcare Specialties Leading the Way In Telemedicine; https://blog.evisit.com/virtual-careblog/top-specialties-for-telemedicine; Retrieved: December 1, 2020

10. Kho J, Gillespie N, Martin-Khan M. A systematic scoping review of change management practices used for telemedicine service implementations. BMC Health Serv Res. 2020 Sep 1;20(1):815. doi: 10.1186/s12913-020-05657-w. PMID: 32873295; PMCID: PMC7461334.

11. Hakim A, Gaviria-Agudelo C, Edwards K, Olson D; PIDS Telehealth Working Group. Pre-Coronavirus Disease 2019 Telehealth Practices Among Pediatric Infectious Diseases Specialists in the United States. J Pediatric Infect Dis Soc. 2020 Nov 16:piaa146. doi: 10.1093/jpids/piaa146. Epub ahead of print. PMID: 33196843; PMCID: PMC7717292.

12. Persaud YK, Portnoy JM. Ten Rules for Implementation of a Telemedicine Program to Care for Patients with Asthma. J Allergy Clin Immunol Pract. 2020 Oct 8:S2213-2198(20)31095-3. doi: 10.1016/j.jaip.2020.10.005. Epub ahead of print. PMID: 33039648; PMCID: PMC7543924.

13. Lee T, Kim L. Telemedicine in Gastroenterology: A Value-Added Service for Patients. Clin Gastroenterol Hepatol. 2020 Mar;18(3):530-533. doi: 10.1016/j.cgh.2019.12.005. Epub 2019 Dec 9. PMID: 31821875.

14. Spivak S, Spivak A, Cullen B, Meuchel J, Johnston D, Chernow R, Green C, Mojtabai R. Telepsychiatry Use in U.S. Mental Health Facilities, 2010-2017. Psychiatr Serv. 2020 Feb 1;71(2):121-127. doi: 
10.1176/appi.ps.201900261. Epub 2019 Oct 16. PMID: 31615370.

15. Dubin JM, Wyant WA, Balaji NC, Ong WL, Kettache RH, Haffaf M, Zouari S, Santillan D, Autrán Gómez AM, Sadeghi-Nejad H, Loeb S, Borin JF, Gomez Rivas J, Grummet J, Ramasamy R, Teoh JYC.

Telemedicine Usage Among Urologists During the COVID-19 Pandemic: Cross-Sectional Study. J Med Internet Res. 2020 Nov 5;22(11):e21875. doi: 10.2196/21875. PMID: 33031047; PMCID: PMC7647472.

16. Gilman M, Stensland J. Telehealth and Medicare: payment policy, current use, and prospects for growth. Medicare Medicaid Res Rev. 2013 Dec 4;3(4):mmrr.003.04.a04. doi:

10.5600/mmrr.003.04.a04. PMID: 24834368; PMCID: PMC4011650.

17. Mended Hearts; Telemedicine's expanded role in cardiac care;

https://mendedhearts.org/story/telemedicines-expanding-role-in-cardiac-care/; Retrieved: September $2,2020$.

18. Nguyen M, Waller M, Pandya A, Portnoy J. A Review of Patient and Provider Satisfaction with Telemedicine. Curr Allergy Asthma Rep. 2020 Sep 22;20(11):72. doi: 10.1007/s11882-020-00969-7. PMID: 32959158; PMCID: PMC7505720.

19. Shachar C, Engel J, Elwyn G. Implications for Telehealth in a Postpandemic Future: Regulatory and Privacy Issues. JAMA. 2020 Jun 16;323(23):2375-2376. doi: 10.1001/jama.2020.7943. PMID: 32421170.

20. Institute for Healthcare Improvement. Recommendations for designing high quality telehealth http://www.ihi.org/communities/blogs/recommendations-for-designing-high-quality-telehealth; Retrieved August 15, 2020.

21. Hebert M. Telehealth success: evaluation framework development. Stud Health Technol Inform. 2001;84(Pt 2):1145-9. PMID: 11604908.

22. Moehr JR, Schaafsma J, Anglin C, Pantazi SV, Grimm NA, Anglin S. Success factors for telehealth--a case study. Int J Med Inform. 2006 Oct-Nov;75(10-11):755-63. doi: 10.1016/j.ijmedinf.2005.11.001. Epub 2006 Jan 4. PMID: 16388982.

23. Dovigi E, Kwok EYL, English JC 3rd. A Framework-Driven Systematic Review of the Barriers and Facilitators to Teledermatology Implementation. Curr Dermatol Rep. 2020 Nov 12:1-9. doi: 10.1007/s13671-020-00323-0. Epub ahead of print. PMID: 33200042; PMCID: PMC7658914.

24. Shapiro SD, Rothman PB. How Academic Health Systems Can Move Forward Once COVID-19 Wanes. JAMA. 2020 Jun 16;323(23):2377-2378. doi: 10.1001/jama.2020.8002. PMID: 32433764.

25. Perrin PB, Pierce BS, Elliott TR. COVID-19 and telemedicine: A revolution in healthcare delivery is at hand. Health Sci Rep. 2020 Jun 3;3(2):e166. doi: 10.1002/hsr2.166. PMID: 32500101; PMCID: PMC7261969.

26. Rajda J, Paz HL. The Future of Virtual Care Services: A Payor's Perspective. Telemed J E Health. 2020 Mar;26(3):267-269. doi: 10.1089/tmj.2019.0020. Epub 2019 May 6. PMID: 31058584.

27. North S. Telemedicine in the Time of COVID and Beyond. J Adolesc Health. 2020 Aug;67(2):145-146. doi: 10.1016/j.jadohealth.2020.05.024. Epub 2020 Jun 27. PMID: 32605827; PMCID: PMC7320687. 
28. Popay J, Roberts H, Sowden A, Petticrew M, Arai L, Rodgers M et al. Guidance on the Conduct of Narrative Synthesis in Systematic Reviews, 2006; https://citeseerx.ist.psu.edu/viewdoc/download? doi=10.1.1.178.3100\&rep=rep1\&type=pdf; Retrieved: August 15, 2020.

29. Iwelunmor J, Plange-Rhule J, Airhihenbuwa CO, Ezepue C, Ogedegbe O. A Narrative Synthesis of the Health Systems Factors Influencing Optimal Hypertension Control in Sub-Saharan Africa. PLoS One. 2015 Jul 15;10(7):e0130193. doi: 10.1371/journal.pone.0130193. PMID: 26176223; PMCID: PMC4503432.

30. Moher D, Liberati A, Tetzlaff J, Altman DG; PRISMA Group. Preferred reporting items for systematic reviews and meta-analyses: the PRISMA statement. J Clin Epidemiol. 2009 Oct;62(10):1006-12. doi: 10.1016/j.jclinepi.2009.06.005. Epub 2009 Jul 23. PMID: 19631508.

31. Dopfer K., Foster, J., Potts, J. Micro-meso-macro; J Evol Econ; 2004. 14: 263-279; DOI: 10.1007/s00191-004-0193-0

32. Smith T, McNeil K, Mitchell R, Boyle B, Ries N. A study of macro-, meso- and micro-barriers and enablers affecting extended scopes of practice: the case of rural nurse practitioners in Australia. BMC Nurs. 2019 Apr 2; 18:14. doi: 10.1186/s12912-019-0337-z. PMID: 30976197; PMCID: PMC6444450.

33. A Review of Frameworks on the Determinants of Health. Canada: Canadian Council on Social Determinants of Health, 2015; http://ccsdh.ca/images/uploads/Frameworks_Report_English.pdf; Retrieved: September 15, 2020.

34. Ly BA, Labonté R, Bourgeault IL, Niang MN. The individual and contextual determinants of the use of telemedicine: A descriptive study of the perceptions of Senegal's physicians and telemedicine projects managers. PLoS One. 2017 Jul 21;12(7):e0181070. doi: 10.1371/journal.pone.0181070. PMID: 28732028; PMCID: PMC5521789.

35. Snilstveit B, Oliver S, Vojtkova M. Narrative approaches to systematic review and synthesis of evidence for international development policy and practice, J Dev Effect. 2012; 4:3, 409-429, DOI: 10.1080/19439342.2012.710641.

36. Portnoy JM, Pandya A, Waller M, Elliott T. Telemedicine and emerging technologies for health care in allergy/immunology. J Allergy Clin Immunol. 2020 Feb;145(2):445-454. doi: 10.1016/j.jaci.2019.12.903. PMID: 32035604.

37. Hare N, Bansal P, Bajowala SS, Abramson SL, Chervinskiy S, Corriel R, Hauswirth DW, Kakumanu S, Mehta R, Rashid Q, Rupp MR, Shih J, Mosnaim GS. Work Group Report: COVID-19: Unmasking Telemedicine. J Allergy Clin Immunol Pract. 2020 Sep;8(8):2461-2473.e3. doi: 10.1016/j.jaip.2020.06.038. Epub 2020 Jun 27. PMID: 32603900; PMCID: PMC7320693.

38. Portnoy JM, Waller M, De Lurgio S, Dinakar C. Telemedicine is as effective as in-person visits for patients with asthma. Ann Allergy Asthma Immunol. 2016 Sep;117(3):241-5. doi: 10.1016/j.anai.2016.07.012. PMID: 27613456.

39. Elliott T, Shih J, Dinakar C, Portnoy J, Fineman S. American College of Allergy, Asthma \& Immunology Position Paper on the Use of Telemedicine for Allergists. Ann Allergy Asthma Immunol. 2017 
Dec;119(6):512-517. doi: 10.1016/j.anai.2017.09.052. Epub 2017 Nov 2. PMID: 29103799.

40. Chongmelaxme B, Lee S, Dhippayom T, Saokaew S, Chaiyakunapruk N, Dilokthornsakul P. The Effects of Telemedicine on Asthma Control and Patients' Quality of Life in Adults: A Systematic Review and Meta-analysis. J Allergy Clin Immunol Pract. 2019 Jan;7(1):199-216.e11. doi: 10.1016/j.jaip.2018.07.015. Epub 2018 Jul 25. PMID: 30055283.

41. Nguyen M, Waller M, Pandya A, Portnoy J. A Review of Patient and Provider Satisfaction with Telemedicine. Curr Allergy Asthma Rep. 2020 Sep 22;20(11):72. doi: 10.1007/s11882-020-00969-7. PMID: 32959158; PMCID: PMC7505720.

42. Greiwe J. Using Telemedicine in a Private Allergy Practice. J Allergy Clin Immunol Pract. 2019 NovDec;7(8):2560-2567. doi: 10.1016/j.jaip.2019.07.012. Epub 2019 Jul 20. PMID: 31336177.

43. Shih J, Portnoy J. Tips for Seeing Patients via Telemedicine. Curr Allergy Asthma Rep. 2018 Aug 15;18(10):50. doi: 10.1007/s11882-018-0807-5. PMID: 30112587.

44. Click B, Regueiro M. The Inflammatory Bowel Disease Medical Home: From Patients to Populations. Inflamm Bowel Dis. 2019 Nov 14;25(12):1881-1885. doi: 10.1093/ibd/izz062. PMID: 30934057.

45. Beard JA, Franco DL, Click BH. The Burden of Cost in Inflammatory Bowel Disease: A Medical Economic Perspective and the Future of Value-Based Care. Curr Gastroenterol Rep. 2020 Jan 30;22(2):6. doi: 10.1007/s11894-020-0744-Z. PMID: 32002671.

46. Regueiro M, Click B, Holder D, Shrank W, McAnallen S, Szigethy E. Constructing an Inflammatory Bowel Disease Patient-Centered Medical Home. Clin Gastroenterol Hepatol. 2017 Aug;15(8):11481153.e4. doi: 10.1016/j.cgh.2017.05.026. Epub 2017 Jun 16. PMID: 28624253.

47. Huang VW, Reich KM, Fedorak RN. Distance management of inflammatory bowel disease: systematic review and meta-analysis. World J Gastroenterol. 2014 Jan 21;20(3):829-42. doi: 10.3748/wjg.v20.i3.829. PMID: 24574756; PMCID: PMC3921492.

48. Berg EA, Picoraro JA, Miller SD, Srinath A, Franciosi JP, Hayes CE, Farrell PR, Cole CR, LeLeiko NS. COVID-19-A Guide to Rapid Implementation of Telehealth Services: A Playbook for the Pediatric Gastroenterologist. J Pediatr Gastroenterol Nutr. 2020 Jun;70(6):734-740. doi:

10.1097/MPG.0000000000002749. PMID: 32443021 ; PMCID: PMC7273955.

49. Huntzinger M, Bielefeldt K. Expanding the Scope of Telemedicine in Gastroenterology. Fed Pract. 2018 Aug;35(8):26-31. PMID: 30766378; PMCID: PMC6263446.

50. Allen JI, Kaushal N. New Models of Gastroenterology Practice. Clin Gastroenterol Hepatol. 2018 Jan;16(1):3-6. doi: 10.1016/j.cgh.2017.10.003. Erratum in: Clin Gastroenterol Hepatol. 2018 May;16(5):787. PMID: 29249407.

51. Dobrusin A, Hawa F, Gladshteyn M, Corsello P, Harlen K, Walsh CX, Alaparthi L, Weinstein M, Baig N, Sousa A, Gunaratnam NT. Gastroenterologists and Patients Report High Satisfaction Rates With Telehealth Services During the Novel Coronavirus 2019 Pandemic. Clin Gastroenterol Hepatol. 2020 Oct;18(11):2393-2397.e2. doi: 10.1016/j.cgh.2020.07.014. Epub 2020 Jul 11. PMID: 32663521; PMCID: PMC7352104. 
52. George LA, Cross RK. Remote Monitoring and Telemedicine in IBD: Are We There Yet? Curr Gastroenterol Rep. 2020 Feb 10;22(3):12. doi: 10.1007/s11894-020-0751-0. PMID: 32040650.

53. Bilal M, Sawhney MS, Feuerstein JD. Coronavirus disease-2019: implications for the gastroenterologist. Curr Opin Gastroenterol. 2021 Jan;37(1):23-29. doi:

10.1097/MOG.0000000000000694. PMID: 33074995.

54. Moore MA, Coffman M, Jetty A, Klink K, Petterson S, Bazemore A. Family Physicians Report Considerable Interest in, but Limited Use of, Telehealth Services. J Am Board Fam Med. 2017 MayJun;30(3):320-330. doi: 10.3122/jabfm.2017.03.160201. PMID: 28484064.

55. Powell RE, Henstenburg JM, Cooper G, Hollander JE, Rising KL. Patient Perceptions of Telehealth Primary Care Video Visits. Ann Fam Med. 2017 May;15(3):225-229. doi: 10.1370/afm.2095. PMID: 28483887; PMCID: PMC5422083.

56. Krist AH, DeVoe JE, Cheng A, Ehrlich T, Jones SM. Redesigning Primary Care to Address the COVID-19 Pandemic in the Midst of the Pandemic. Ann Fam Med. 2020 Jul;18(4):349-354. doi:

10.1370/afm.2557. PMID: 32661037; PMCID: PMC7358035.

57. Noel K, Messina C, Hou W, lySchoenfeld E, Kelly G. Tele-transitions of care (TTOC): a 12-month, randomized controlled trial evaluating the use of Telehealth to achieve triple aim objectives. BMC Fam Pract. 2020 Feb 7;21(1):27. doi: 10.1186/s12875-020-1094-5. PMID: 32033535; PMCID: PMC7007639.

58. Phillips RL Jr, Bazemore AW, DeVoe JE, Weida TJ, Krist AH, Dulin MF, Biagioli FE. A Family Medicine Health Technology Strategy for Achieving the Triple Aim for US Health Care. Fam Med. 2015 Sep;47(8):628-35. PMID: 26382121; PMCID: PMC4926766.

59. Martin JC, Avant RF, Bowman MA, Bucholtz JR, Dickinson JR, Evans KL, Green LA, Henley DE, Jones WA, Matheny SC, Nevin JE, Panther SL, Puffer JC, Roberts RG, Rodgers DV, Sherwood RA, Stange KC, Weber CW; Future of Family Medicine Project Leadership Committee. The Future of Family Medicine: a collaborative project of the family medicine community. Ann Fam Med. 2004 Mar-Apr;2 Suppl 1(Suppl 1):S3-32. doi: 10.1370/afm.130. PMID: 15080220; PMCID: PMC1466763.

60. Rubin R. COVID-19's Crushing Effects on Medical Practices, Some of Which Might Not Survive. JAMA. 2020 Jul 28;324(4):321-323. doi: 10.1001/jama.2020.11254. PMID: 32556122.

61. Wakefield BJ, Koopman RJ, Keplinger LE, Bomar M, Bernt B, Johanning JL, Kruse RL, Davis JW, Wakefield DS, Mehr DR. Effect of home telemonitoring on glycemic and blood pressure control in primary care clinic patients with diabetes. Telemed J E Health. 2014 Mar;20(3):199-205. doi: 10.1089/tmj.2013.0151. Epub 2014 Jan 3. PMID: 24404819; PMCID: PMC3934666.

62. Kuehn BM. Telemedicine Helps Cardiologists Extend Their Reach. Circulation. 2016 Oct 18;134(16):1189-1191. doi: 10.1161/CIRCULATIONAHA.116.025282. PMID: 27754948.

63. Hale TM, Jethwani K, Kandola MS, Saldana F, Kvedar JC. A Remote Medication Monitoring System for Chronic Heart Failure Patients to Reduce Readmissions: A Two-Arm Randomized Pilot Study. J Med Internet Res. 2016 Apr 17;18(5):e91. doi: 10.2196/jmir.5256. Erratum in: J Med Internet Res. 2019 Feb 05;21(2):e13125. PMID: 27154462; PMCID: PMC4890732. 
64. Varma N, Marrouche NF, Aguinaga L, Albert CM, Arbelo E, Choi JI, Chung MK, Conte G, Dagher L, Epstein LM, Ghanbari H, Han JK, Heidbuchel H, Huang H, Lakkireddy DR, Ngarmukos T, Russo AM, Saad EB, Saenz Morales LC, Sandau KE, Sridhar ARM, Stecker EC, Varosy PD. HRS/EHRA/APHRS/LAHRS/ACC/AHA Worldwide Practice Update for Telehealth and Arrhythmia Monitoring During and After a Pandemic. Circ Arrhythm Electrophysiol. 2020 Jul;13(7):e009007. doi: 10.1161/CIRCEP.120.009007. Epub 2020 Jul 21. PMID: 32692972; PMCID: PMC7482618.

65. Schwamm LH, Chumbler N, Brown E, Fonarow GC, Berube D, Nystrom K, Suter R, Zavala M, Polsky D, Radhakrishnan K, Lacktman N, Horton K, Malcarney MB, Halamka J, Tiner AC; American Heart Association Advocacy Coordinating Committee. Recommendations for the Implementation of Telehealth in Cardiovascular and Stroke Care: A Policy Statement From the American Heart Association. Circulation. 2017 Feb 14;135(7):e24-e44. doi: 10.1161/CIR.0000000000000475. Epub 2016 Dec 20. PMID: 27998940.

66. Riegel B, Moser DK, Buck HG, Dickson VV, Dunbar SB, Lee CS, Lennie TA, Lindenfeld J, Mitchell JE, Treat-Jacobson DJ, Webber DE; American Heart Association Council on Cardiovascular and Stroke Nursing; Council on Peripheral Vascular Disease; and Council on Quality of Care and Outcomes Research. Self-Care for the Prevention and Management of Cardiovascular Disease and Stroke: A Scientific Statement for Healthcare Professionals From the American Heart Association. J Am Heart Assoc. 2017 Aug 31;6(9):e006997. doi: 10.1161/JAHA.117.006997. PMID: 28860232; PMCID: PMC5634314.

67. Chowdhury D, Hope KD, Arthur LC, Weinberger SM, Ronai C, Johnson JN, Snyder CS. Telehealth for Pediatric Cardiology Practitioners in the Time of COVID-19. Pediatr Cardiol. 2020 Aug;41(6):10811091. doi: 10.1007/s00246-020-02411-1. Epub 2020 Jul 12. PMID: 32656626; PMCID: PMC7354365.

68. Dolan J, Mandras S, Mehta JP, Navas V, Tarver J, Chakinala M, Rahaghi F. Reducing rates of readmission and development of an outpatient management plan in pulmonary hypertension: lessons from congestive heart failure management. Pulm Circ. 2020 Dec 7;10(4):2045894020968471. doi: 10.1177/2045894020968471. PMID: 33343880; PMCID: PMC7727062.

69. Schwamm LH, Holloway RG, Amarenco P, Audebert HJ, Bakas T, Chumbler NR, Handschu R, Jauch EC, Knight WA 4th, Levine SR, Mayberg M, Meyer BC, Meyers PM, Skalabrin E, Wechsler LR; American Heart Association Stroke Council; Interdisciplinary Council on Peripheral Vascular Disease. A review of the evidence for the use of telemedicine within stroke systems of care: a scientific statement from the American Heart Association/American Stroke Association. Stroke. 2009 Jul;40(7):2616-34. doi: 10.1161/STROKEAHA.109.192360. Epub 2009 May 7. PMID: 19423852.

70. MacKinnon GE, Brittain EL. Mobile Health Technologies in Cardiopulmonary Disease. Chest. 2020 Mar;157(3):654-664. doi: 10.1016/j.chest.2019.10.015. Epub 2019 Oct 31. PMID: 31678305; PMCID: PMC7078586.

71. Blood AJ, Fischer CM, Fera LE, MacLean TE, Smith KV, Dunning JR, Bosque-Hamilton JW, Aronson SJ, Gaziano TA, MacRae CA, Matta LS, Mercurio-Pinto AA, Murphy SN, Scirica BM, Wagholikar K, Desai AS. Rationale and design of a navigator-driven remote optimization of guideline-directed 
medical therapy in patients with heart failure with reduced ejection fraction. Clin Cardiol. 2020 Jan;43(1):4-13. doi: 10.1002/clc.23291. Epub 2019 Nov 14. PMID: 31725920; PMCID: PMC6954374.

72. Mongelli F, Georgakopoulos P, Pato MT. Challenges and Opportunities to Meet the Mental Health Needs of Underserved and Disenfranchised Populations in the United States. Focus (Am Psychiatr Publ). 2020 Jan;18(1):16-24. doi: 10.1176/appi.focus.20190028. Epub 2020 Jan 24. PMID: 32047393; PMCID: PMC7011222.

73. Yellowlees P, Shore J, Roberts L; American Telemedicine Association. Practice guidelines for videoconferencing-based telemental health - October 2009. Telemed J E Health. 2010 Dec;16(10):1074-89. doi: 10.1089/tmj.2010.0148. PMID: 21186991.

74. Shore JH, Yellowlees P, Caudill R, Johnston B, Turvey C, Mishkind M, Krupinski E, Myers K, Shore P, Kaftarian E, Hilty D. Best Practices in Videoconferencing-Based Telemental Health April 2018. Telemed J E Health. 2018 Nov;24(11):827-832. doi: 10.1089/tmj.2018.0237. Epub 2018 Oct 24. PMID: 30358514.

75. Shulman M, John M, Kane JM. Home-Based Outpatient Telepsychiatry to Improve Adherence With Treatment Appointments: A Pilot Study. Psychiatr Serv. 2017 Jul 1;68(7):743-746. doi: 10.1176/appi.ps.201600244. Epub 2017 Mar 1. PMID: 28245700; PMCID: PMC5848466.

76. Yellowlees P, Burke Parish M, González Á, Chan S, Hilty D, losif AM, McCarron R, Odor A, Scher L, Sciolla A, Shore J, Xiong G. Asynchronous Telepsychiatry: A Component of Stepped Integrated Care. Telemed J E Health. 2018 May;24(5):375-378. doi: 10.1089/tmj.2017.0103. Epub 2017 Oct 12. PMID: $29024612 ;$ PMCID: PMC5953215.

77. Yuen EK, Gros DF, Price M, Zeigler S, Tuerk PW, Foa EB, Acierno R. Randomized Controlled Trial of Home-Based Telehealth Versus In-Person Prolonged Exposure for Combat-Related PTSD in Veterans: Preliminary Results. J Clin Psychol. 2015 Jun;71(6):500-12. doi: 10.1002/jclp.22168. Epub 2015 Mar 25. PMID: 25809565.

78. Hubley S, Lynch SB, Schneck C, Thomas M, Shore J. Review of key telepsychiatry outcomes. World J Psychiatry. 2016 Jun 22;6(2):269-82. doi: 10.5498/wjp.v6.i2.269. PMID: 27354970; PMCID: PMC4919267.

79. Antonacci DJ, Bloch RM, Saeed SA, Yildirim Y, Talley J. Empirical evidence on the use and effectiveness of telepsychiatry via videoconferencing: implications for forensic and correctional psychiatry. Behav Sci Law. 2008;26(3):253-69. doi: 10.1002/bsl.812. PMID: 18548519.

80. Mahmoud H, Vogt E. Telepsychiatry: an Innovative Approach to Addressing the Opioid Crisis. J Behav Health Serv Res. 2019 Oct;46(4):680-685. doi: 10.1007/s11414-018-9611-1. PMID: 29600491.

81. Ramtekkar U, Bridge JA, Thomas G, Butter E, Reese J, Logan E, Lin S, Axelson D. Pediatric Telebehavioral Health: A Transformational Shift in Care Delivery in the Era of COVID-19. JMIR Ment Health. 2020 Sep 18;7(9):e20157. doi: 10.2196/20157. PMID: 32525485; PMCID: PMC7505681.

82. Bashshur RL, Krupinski EA, Thrall JH, Bashshur N. The Empirical Foundations of Teleradiology and Related Applications: A Review of the Evidence. Telemed J E Health. 2016 Nov;22(11):868-898. doi: 10.1089/tmj.2016.0149. Epub 2016 Sep 1. PMID: 27585301; PMCID: PMC5107673. 
83. Krupinski E, McNeill K, Haber K, Ovitt T. High-volume teleradiology service: focus on radiologist satisfaction. J Digit Imaging. 2003 Jun;16(2):203-9. doi: 10.1007/s10278-003-1658-7. Epub 2003 Oct 2. PMID: 14517723; PMCID: PMC3046471.

84. Siegal DS, Wessman B, Zadorozny J, Palazzolo J, Montana A, Rawson JV, Norbash A, Brown ML. Operational Radiology Recovery in Academic Radiology Departments After the COVID-19 Pandemic: Moving Toward Normalcy. J Am Coll Radiol. 2020 Sep;17(9):1101-1107. doi: 10.1016/j.jacr.2020.07.004. Epub 2020 Jul 11. PMID: 32682744.

85. Johnson ND. Teleradiology 2010: technical and organizational issues. Pediatr Radiol. 2010 Jun;40(6):1052-5. doi: 10.1007/s00247-010-1619-5. Epub 2010 Apr 30. PMID: 20432025.

86. Pedrosa I, Browning T, Kwon JK, Morriss M, Matsler L, Pinho MC, Lamus D, Pillai A, Karow SP, Garinn J, Brewington C, Zeikus E, Rofsky NM. Response to COVID-19: Minimizing Risks, Addressing Challenges and Maintaining Operations in a Complex Academic Radiology Department. J Comput Assist Tomogr. 2020 Jul/Aug;44(4):479-484. doi: 10.1097/RCT.0000000000001040. PMID: 32433251; PMCID: PMC7448714.

87. Hryhorczuk AL, Hanneman K, Eisenberg RL, Meyer EC, Brown SD. Radiologic Professionalism in Modern Health Care. Radiographics. 2015 Oct;35(6):1779-88. doi: 10.1148/rg.2015150041. PMID: 26466185.

88. Itri JN. Patient-centered Radiology. Radiographics. 2015 Oct;35(6):1835-46. doi: 10.1148/rg.2015150110. PMID: 26466190.

89. Brown NA. State Medicaid and private payer reimbursement for telemedicine: An overview. J Telemed Telecare. 2006;12 Suppl 2:S32-9. doi: 10.1258/135763306778393108. PMID: 16989672.

90. Weinstein RS, Lopez AM, Joseph BA, Erps KA, Holcomb M, Barker GP, Krupinski EA. Telemedicine, telehealth, and mobile health applications that work: opportunities and barriers. Am J Med. 2014 Mar;127(3):183-7. doi: 10.1016/j.amjmed.2013.09.032. Epub 2013 Oct 29. PMID: 24384059.

91. Medical Group Management Association. COVID-19 financial impact on medical practices; https://www.mgma.com/resources/government-programs/covid-19-financial-impact-on-medicalpractices; Retrieved: September 1, 2020.

92. Boland GW. The impact of teleradiology in the United States over the last decade: driving consolidation and commoditization of radiologists and radiology services. Clin Radiol. 2009 May;64(5):457-60; discussion 461-2. doi: 10.1016/j.crad.2008.11.010. Epub 2009 Feb 15. PMID: 19348838.

93. American College of Cardiology. Telehealth in cardiology: The future is today; https://www.acc.org/membership/sections-and-councils/health-care-innovation-section/sectionupdates/2019/11/26/12/42/telehealth-in-cardiology-the-future-is-today; Retrieved: September 10, 2020.

94. Ramos, V. Contributions to the history of Telemedicine of the TICs. 2010; 10.1109/HISTELCON.2010.5735269. 
95. Marjoua Y, Bozic KJ. Brief history of quality movement in US healthcare. Curr Rev Musculoskelet Med. 2012;5(4):265-273. doi:10.1007/s12178-012-9137-8

96. Riddle MS, DuPont HL, Connor BA. ACG Clinical Guideline: Diagnosis, Treatment, and Prevention of Acute Diarrheal Infections in Adults. Am J Gastroenterol. 2016 May;111(5):602-22. doi: 10.1038/ajg.2016.126. Epub 2016 Apr 12. PMID: 27068718.

97. Saeed S., Bloch R., Diamond J. Telepsychiatry: Overcoming barriers to implementation. Current psychiatry. 2012. 11. 28-31.

98. Welch BM, Harvey J, O'Connell NS, McElligott JT. Patient preferences for direct-to-consumer telemedicine services: a nationwide survey. BMC Health Serv Res. 2017 Nov 28;17(1):784. doi: 10.1186/s12913-017-2744-8. PMID: 29183372; PMCID: PMC5704580.

99. Polinski JM, Barker T, Gagliano N, Sussman A, Brennan TA, Shrank WH. Patients' Satisfaction with and Preference for Telehealth Visits. J Gen Intern Med. 2016 Mar;31(3):269-75. doi: 10.1007/s11606015-3489-x. Epub 2015 Aug 13. PMID: 26269131; PMCID: PMC4762824.

100. Barnett ML, Ray KN, Souza J, Mehrotra A. Trends in Telemedicine Use in a Large Commercially Insured Population, 2005-2017. JAMA. 2018 Nov 27;320(20):2147-2149. doi: 10.1001/jama.2018.12354. PMID: 30480716; PMCID: PMC6349464.

101. American Well Telehealth index: 2019 consumer survey. 2019. Available from:https://static.americanwell.com/app/uploads/2019/07/American-Well-Telehealth-Index-2019Consumer-Survey-eBook2.pdf

102. Portnoy J, Waller M, Elliott T. Telemedicine in the Era of COVID-19. J Allergy Clin Immunol Pract. 2020;8(5):1489-1491. doi:10.1016/j.jaip.2020.03.008

103. Cowan KE, McKean AJ, Gentry MT, Hilty DM. Barriers to Use of Telepsychiatry: Clinicians as Gatekeepers. Mayo Clin Proc. 2019 Dec; 94(12):2510-2523. doi: 10.1016/j.mayocp.2019.04.018. PMID: 31806104.

104. Adler-Milstein J, Kvedar J, Bates DW. Telehealth among US hospitals: several factors, including state reimbursement and licensure policies, influence adoption. Health Aff (Millwood). 2014 Feb;33(2):20715. doi: 10.1377/hlthaff.2013.1054. PMID: 24493762.

\section{Figures}




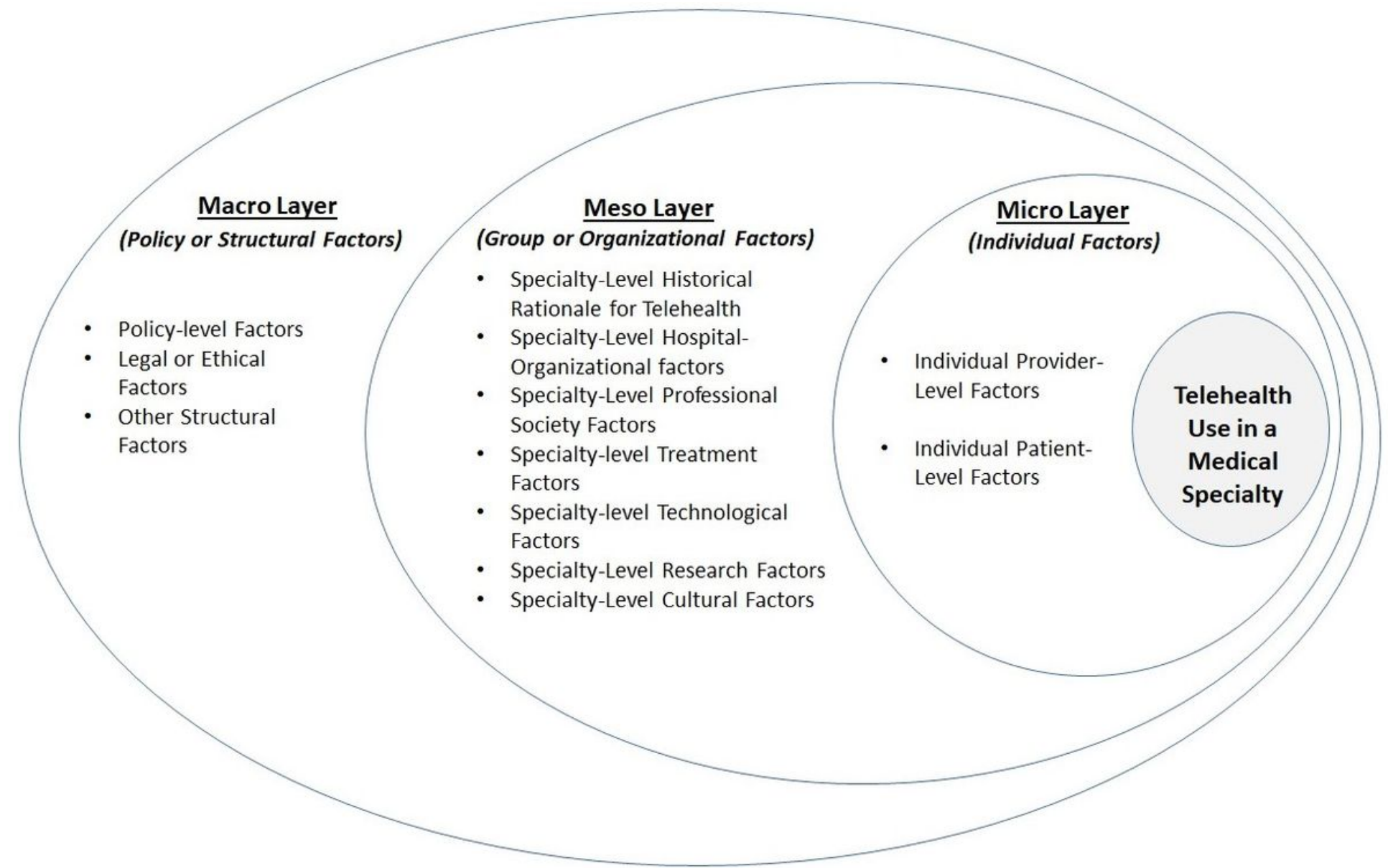

Figure 1

Conceptual Framework 

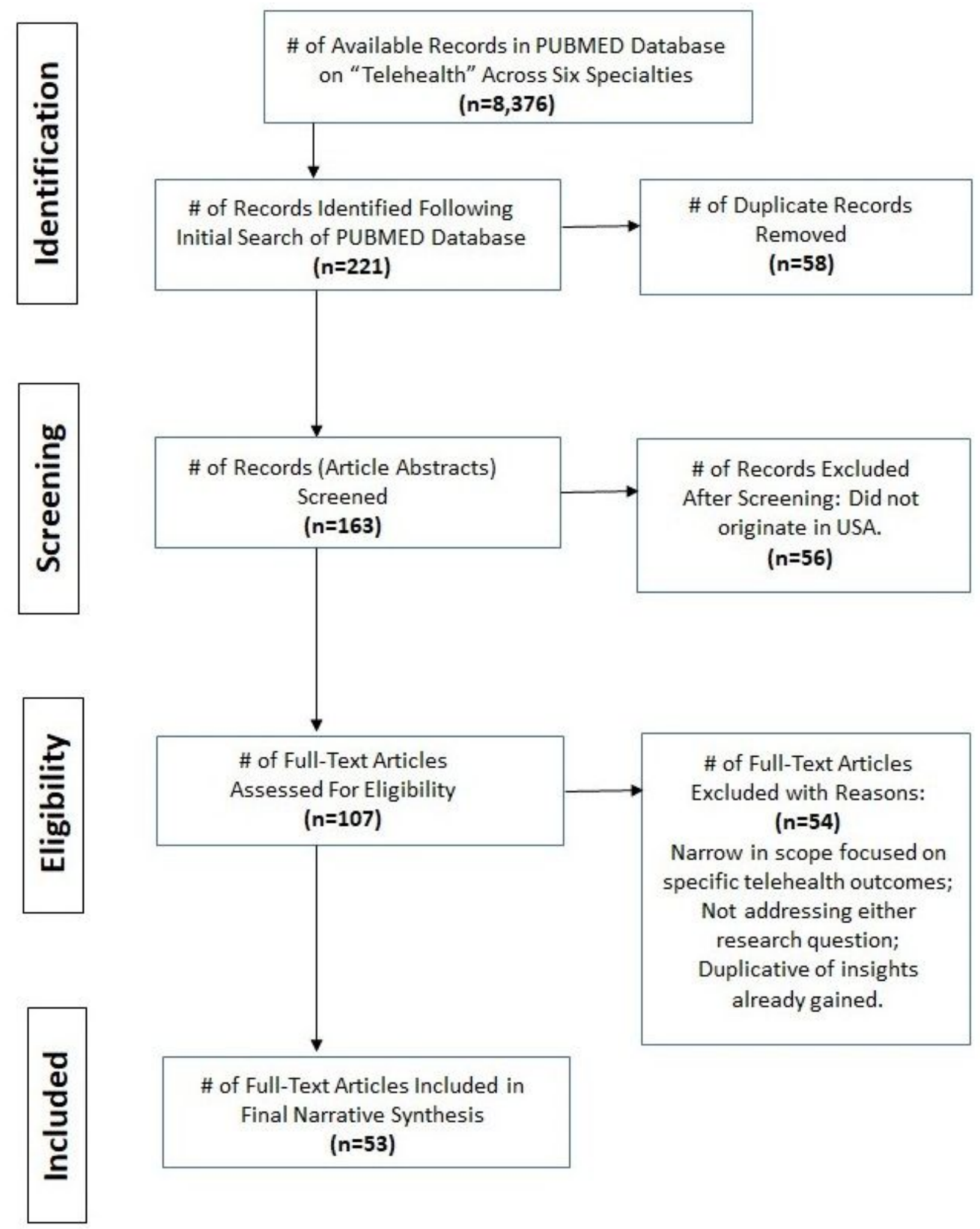

\section{Figure 2}

Article Selection Flow Chart

\section{Supplementary Files}

This is a list of supplementary files associated with this preprint. Click to download. 
- Appendix1PRISMAchecklist.doc

- Appendix2ResearchProtocol.docx

- Appendix3RawDatasetTextualSummariesforSynthesis.xlsx 